\section{OPEN ACCESS}

Edited by:

Qiyuan Yang,

University of Massachusetts Medical

School, United States

Reviewed by:

Marcos Lopez,

University of Puerto Rico, Puerto Rico

Daniel Carneiro Moreira,

University of Brasilia, Brazil

${ }^{*}$ Correspondence:

Liuqin $\mathrm{He}$

285687180@qq.com

Tiejun Li

tjli@isa.ac.cn

Yulong Yin

yinyulong@isa.ac.cn

Specialty section

This article was submitted to

Redox Physiology,

a section of the journal

Frontiers in Physiology

Received: 27 November 2020

Accepted: 12 March 2021

Published: 08 April 2021

Citation:

Han H, Liu Z, Yin J, Gao J, He L,

Wang C, Hou R, He X, Wang G, Li T and Yin Y (2021) D-Galactose Induces Chronic Oxidative Stress and Alters

Gut Microbiota in Weaned Piglets.

Front. Physiol. 12:634283.

doi: 10.3389/fphys.2021.634283

\title{
D-Galactose Induces Chronic Oxidative Stress and Alters Gut Microbiota in Weaned Piglets
}

Hui Han 1,2, Zemin Liu1,3, Jie Yin ${ }^{4}$, Jing Gao5,6, Liuqin He 1,7*, Chenyu Wang 1,3, Ruoxin Hou ${ }^{1,3}$, Xingguo $\mathrm{He}^{8}$, Guoqiang Wang ${ }^{8}$, Tiejun $\mathrm{Li}^{1,3 *}$ and Yulong Yin ${ }^{1,3,7 *}$

${ }^{1}$ Key Laboratory of Agro-ecological Processes in Subtropical Region, Hunan Provincial Key Laboratory of Animal Nutritional Physiology and Metabolic Process, National Engineering Laboratory for Pollution Control and Waste Utilization in Livestock and Poultry Production, Institute of Subtropical Agriculture, Chinese Academy of Sciences, Changsha, China, ${ }^{2}$ State Key Laboratory of Animal Nutrition, Institute of Animal Science, Chinese Academy of Agricultural Sciences, Beijing, China, ${ }^{3}$ College of Advanced Agricultural Sciences, University of Chinese Academy of Sciences, Beijing, China, ${ }^{4}$ College of Animal Science and Technology, Hunan Agricultural University, Changsha, China, ${ }^{5}$ Research Institute of Oil Tea Camellia, Hunan Academy of Forestry, Changsha, China, ${ }^{6}$ National Engineering Research Center for Oil Tea Camellia, Changsha, China, ${ }^{7}$ Hunan International Joint Laboratory of Animal Intestinal Ecology and Health, Laboratory of Animal Nutrition and Human Health, College of Life Sciences, Hunan Normal University, Changsha, China, ${ }^{8}$ Changsha Lvye Bio-Technology Co., Ltd., Changsha, China

Oxidative stress commonly occurs in pig production, which can severely damage the intestinal function of weaned piglets. This study was conducted to investigate the effects of D-galactose with different levels used to induce chronic oxidative stress on growth performance, intestinal morphology and gut microbiota in weaned piglets. The results showed that addition of 10 and $20 \mathrm{~g} / \mathrm{kg}$ BW D-galactose reduced average daily gain and average daily feed intake from the first to the third week. $10 \mathrm{~g} / \mathrm{kg} \mathrm{BW} \mathrm{D-}$ galactose increased the concentration of serum MDA at the second and third week. $10 \mathrm{~g} / \mathrm{kg}$ BW D-galactose significantly influenced the jejunal and ileal expressions of GPX1, CAT1, and MnSOD. The results of 16S rRNA sequencing showed that compared with the control, 10 and $20 \mathrm{~g} / \mathrm{kg}$ BW D-galactose significantly decreased the relative abundance of Tenericutes, Erysipelotrichia, Erysipelotrichales, and Erysipelotrichaceae, while increased the relative abundance of Negativicutes, Selenomonnadales, and Veillonellaceae. The results indicated that treatment with $10 \mathrm{~g} / \mathrm{kg} \mathrm{BW} /$ day D-galactose for 3 weeks could induce chronic oxidative stress, reduce the growth performance and alter gut microbiota in weaned piglets.

Keywords: D-galactose, chronic oxidative stress, gut microbiota, weaned piglets, growth performance

\section{INTRODUCTION}

Oxidative stress is regarded as an imbalance between the oxidative and antioxidative reactions (Jiang et al., 2016; Yahata and Hamaoka, 2016). Under normal physiological circumstance, reactive oxygen species (ROS) are maintained homeostasis and excessive ROS are eliminated by the antioxidant system including non-enzymatic components and antioxidant enzymes, 
such as glutathione peroxidase (GSH-Px), catalase (CAT), and superoxide dismutase (SOD) (Jiang et al., 2016). However, the imbalance between the prooxidant and antioxidant activity will lead to the excess production of ROS, which can cause oxidative stress and do harm to cellular DNA, protein, and lipid (Ali et al., 2015; Jiang et al., 2016).

Post-weaning piglets are subjected to oxidative stress caused by the changes of nutritional source, physical and social environments (Yin et al., 2014). During weaning, piglets have to be suddenly separated from the sow, transported to a different physical environment, regrouped with unfamiliar piglets from other litters, changed from sow watery milk to feeding on solid feed, and exposed to increased dietary or environmental pathogens and antigens (Campbell et al., 2013). Amounting studies have shown that gastrointestinal tract is highly susceptible to oxidative stress and previous investigations have revealed that oxidative stress can damage the intestinal barrier functions and change the gut microbiome in piglets (He et al., 2017; Zheng et al., 2017; Cao et al., 2018; Zhang et al., 2018). Gut microbiota and intestinal barrier are strongly related to maintaining homeostasis in intestine as well as other organs of host (Dam et al., 2019). Disordered gut microbiota can produce excessive ROS to induce oxidative stress that in turn lead to intestinal inflammation and even various chronic diseases related to inflammation (Marciano and Vajro, 2017; Vasquez et al., 2019). However, some gut microbial metabolites, such as SCFAs, are able to alleviate oxidative stress (Andrade-Oliveira et al., 2015; Rose et al., 2018). Treatment with diquat and polyunsaturated fatty acids are always used to induce acute or chronic oxidative stress in piglets (Di Giancamillo et al., 2015; Shen et al., 2015; Cao et al., 2018; Rossi et al., 2019). However, there are several disadvantages to using diquat or polyunsaturated fatty acids as treatments. Firstly, intraperitoneal injection of diquat can cause severe stress in piglets, such as anorexia and diarrhea, which might affect the results of following study (Xu et al., 2018). Secondly, vegetable oil and fish oil enriched in polyunsaturated fatty acids are commonly used to induced chronic oxidative stress but the fresh oil need to be pre-oxidized and determined the peroxide value before supplementation, which is a little complex (Shan et al., 2009; Di Giancamillo et al., 2015; Wang et al., 2016).

To determine the mechanism whereby oxidative stress exerts effects on intestinal health and gut microbiota, the chronic oxidative stress is suitable for observing the change trend of piglets than acute oxidative stress. D-galactose, as a monosaccharide sugar, can be metabolized by mammalian animals. However, excess administration of D-galactose can induce oxidative stress in the body by three different ways. Firstly, D-galactose, as a reducing sugar, can react with the free amines of amino acids and produce a Schiff base (Shwe et al., 2018). The Schiff is oxidized and form advanced glycation end products, which can interact with specific receptors and then induce the production of reactive oxygen species (ROS) (Zhang et al., 2016). Excessive ROS cause excess peroxidation of proteins, lipid, and DNA. Secondly, high level of D-galactose can induce the production of hydrogen peroxide and MDA and inhibit the levels of antioxidant enzymes, such as SOD and GSH (Shwe et al., 2018; Zhang Z. et al., 2019). Thirdly,
D-galactose is reduced by galactose reductase and over-supply Dgalactose converts into galactitol, which cannot be metabolized and then accumulate in the cell to generate amounts of ROS (Thakur et al., 2017). It is well known that D-galactose treatment is widely used as a chronic model to induce oxidative stress in rats and mice (Shen et al., 2002; Qian et al., 2018; Zhang X. et al., 2019). However, there is currently no study on chronic oxidative stress induced by $\mathrm{D}$-galactose in a pig model. Thus, our study was conducted to test whether Dgalactose could be used as a model to induce chronic oxidative stress and investigate the effects of chronic oxidative stress on growth performance, intestinal morphology and microbiota in weaned piglets.

\section{MATERIALS AND METHODS}

\section{Animal and Experimental Design}

This study was approved by the animal welfare committee of the Institute of Subtropical Agriculture, Chinese Academy of Sciences (2013020; Changsha, China). Thirty-two crossbred (Duroc $\times$ Landrace $\times$ Yorkshire; average body weight $(\mathrm{BW})=5.44 \pm 0.26 \mathrm{~kg}$ ) healthy piglets weaned at 21 days were randomly divided into four treatments $(n=8 /$ group): (1) control group, piglets were fed the basal diet; (2) $5 \mathrm{~g} / \mathrm{kg}$ BW D-galactose group, piglets were fed with the basal diet supplemented with D-galactose at a dosage of $5 \mathrm{~g} / \mathrm{kg} \mathrm{BW/day;}$ (3) $10 \mathrm{~g} / \mathrm{kg} \mathrm{BW} \mathrm{D}$-galactose group, piglets were fed with the basal diet supplemented with D-galactose at a dosage of $10 \mathrm{~g} / \mathrm{kg}$ BW/day; and (4) $20 \mathrm{~g} / \mathrm{kg} \mathrm{BW}$ D-galactose group, piglets were fed the basal diet supplemented with D-galactose at a dosage of $20 \mathrm{~g} / \mathrm{kg} \mathrm{BW} /$ day. The BW were measured weekly and the volume of D-galactose were calculated according to BW. Every morning, after cleaning the through and weighing the remaining feed, D-galactose was mixed in a small amount of diet and given to the piglets. Then the piglets were fed with diet without D-galactose until they eat up the diet containing D-galactose. The composition and nutrient levels of the basal diet met the nutrient specifications for 5 to $10 \mathrm{~kg} \mathrm{BW}$ pig according to recommendations of the National Research Council (2012) (Table 1). During the whole experiment, piglets were housed individually and given free access to water. The average daily feed intake (ADFI) was monitored daily and ADFI and final average daily gain (ADG) were calculated weekly. The duration of the overall experiment was 21 days. The administration dosages of D-galactose (Hubei Yuying Biotechnology Co., Ltd., Yichang, Hubei, China) were adopted according to the previous mice experiments (Ma et al., 2018; Sun et al., 2018; Sha et al., 2019).

\section{Sample Collection}

Blood sample of the piglets in every week were collected and serum were obtained by centrifugation at 3,000 rpm for $10 \mathrm{~min}$ under $4^{\circ} \mathrm{C}$ and stored at $-20^{\circ} \mathrm{C}$ until analysis according to our previous studies (Yin et al., 2017). On days 21, after blood sampling, all piglets were anesthetized with an intravenous injection of sodium pentobarbital $(50 \mathrm{mg} / \mathrm{kg} \mathrm{BW})$ and bled by 
TABLE 1 | Composition and nutrient level of basal diet.

\begin{tabular}{|c|c|}
\hline Item & Composition \% \\
\hline Corn & 55.59 \\
\hline Soybean oil & 0.72 \\
\hline Glucose & 1 \\
\hline Sucrose & 2 \\
\hline Expanded soybean & 8 \\
\hline Soybean meal & 21.5 \\
\hline Fish meal & 4 \\
\hline Whey power & 3.2 \\
\hline $\mathrm{NaCl}$ & 0.4 \\
\hline Limestone & 0.55 \\
\hline $\mathrm{CaHCO}_{3}$ & 0.87 \\
\hline $\mathrm{ZnO}$ & 0.3 \\
\hline Lysine & 0.4 \\
\hline Methionine & 0.2 \\
\hline Threonine & 0.14 \\
\hline Tryptophan & 0.03 \\
\hline Choline chloride & 0.1 \\
\hline Premix ${ }^{\star}$ & 1 \\
\hline \multicolumn{2}{|l|}{ Nutritional Level } \\
\hline $\mathrm{CP}$ & 19.74 \\
\hline Lysine & 1.39 \\
\hline Methionine + Cysteine & 0.84 \\
\hline Threonine & 0.88 \\
\hline Tryptophan & 0.24 \\
\hline
\end{tabular}

*Premix provided the following per kilogram of the diet: Sepiolite, $6.043 \mathrm{~g}$; pig vitamin, 750 mg; Fe, 150 mg; Cu, 150 mg; Man, 80 mg; Zn, 120 mg; Se, 0.3 mg; Co, $1 \mathrm{mg} ; \mathrm{l}, 0.3 \mathrm{mg}$; VB4 1,000 mg.

exsanguination. The small intestine was dissected free of the mesentery and sampled on a chilled stainless-steel tray. Ten-cm segments were collected from the proximal jejunum and distal ileum, respectively, thoroughly flushed with ice-cold phosphatebuffered saline, and then frozen in liquid nitrogen and stored at $-80^{\circ} \mathrm{C}$ for the analysis of gene expression, one segment was fixed in $4 \%$ paraformaldehyde-PBS for examination of intestinal morphology. Colonic digesta was collected to determine gut microbiota. The heart, liver, spleen, and kidney were isolated and weighted. Relative organ weight $(\mathrm{g} / \mathrm{kg})=$ organ weight (g)/body weight (kg).

\section{Intestinal Histomorphology}

Jejunal and ileal sections were fixed with $4 \%$ paraformaldehydePBS overnight, then dehydrated and embedded in paraffin blocks and sectioned at 5-7 $\mu \mathrm{m}$. The sections were further deparaffinized and hydrated, and then stained with hematoxylin eosin (H\&E). Villus length and crypt depth were performed using image J software.

\section{Serum Biochemical Parameters and Amino Acids Determination}

Serum biochemical parameters, including total protein (TP), albumin (ALB), alanine transaminase (ALT), glutamic oxalacetic transaminase (AST), alkaline phosphatase (ALP), cholesterol
(CHOL), high density lipoprotein (HDL), low density lipoprotein (LDL), were determined using automatic biochemical analyzer (fully automatic bio analysis machine cobas c311, Roche Co., Ltd.). Serum amino acids contents (His, Ser, Arg, Gly, Asp, Glu, Thr, Ala, Pro, Cys, Lys, Tyr, Met, Val, Ile, Leu, Phe, and Trp) were measured by High-speed Amino Acid Analyzer L-8900 (Japan) according to our previous studies (Duan et al., 2014).

\section{Determination of Serum Antioxidant Enzymes Activities and MDA Level}

The activities of glutathione peroxidase (GSH-Px), catalase (CAT), and superoxide dismutase (SOD) and the level of malondialdehyde (MDA) in serum were measured with corresponding assay kits (Nanjing Bioengineering Institute, Nanjing, China) in accordance with the manufactures' instructions. The GSH-Px activity was measured based on the principle that oxidation of glutathione (GSH) and hydrogen peroxide could be catalyzed by GSH-Px to produce oxidized glutathione (GSSG) and $\mathrm{H}_{2} \mathrm{O}$. GSH can act with 5,5'-dithiobis-2-nitrobenzoic acid to produce yellow 5-thio-2-nitrobenzoic acid. The change in absorbance during the conversion of GSH to GSSG was measured at $412 \mathrm{~nm}$. The SOD activity was measured based on the auto-oxidation of hydroxylamine. The developed blue color was measured at $550 \mathrm{~nm}$. CAT reacts with $\mathrm{H}_{2} \mathrm{O}_{2}$ and this reaction can be terminated by molybdenum to produce a yellow product. The activity of CAT was measured based on the decrease in absorbance at $405 \mathrm{~nm}$ due to the degradation of $\mathrm{H}_{2} \mathrm{O}_{2}$. The MDA level was measured based on the principle that MDA can react with thiobarbituric acid (TBA) to produce a red product (MDA-TBA), which was measured at $532 \mathrm{~nm}$. The activities of GSH-Px, CAT, and SOD were expressed in $\mathrm{U} / \mathrm{mL}$, and the MDA level was shown in $\mathrm{nmol} / \mathrm{mL}$, respectively.

\section{Real-Time Quantitative (RT-PCR)}

Total RNA from jejunum and ileum samples were isolated from liquid nitrogen using TRIZOL reagent (Invitrogen, United States) and then treated with DNase I (Invitrogen, United States) according to the manufacturer's instructions. The reverse transcription was conducted at $37^{\circ} \mathrm{C}$ for $15 \mathrm{~min}, 85^{\circ} \mathrm{C}$ for $5 \mathrm{~s}$. Primers used in this study were presented in the previous studies (Table 2). $\beta$-actin was chosen as the house-keeping gene to normalize target gene levels. Real-time PCR was performed according to our previous study (Yin et al., 2018). Relative expression was expressed as a ratio of the target gene to the control gene using the formula $2^{-(\Delta \Delta \mathrm{Ct})}$, where $\Delta \Delta \mathrm{Ct}=\left(\mathrm{Ct}_{\text {Target }}-\mathrm{Ct}_{\beta}\right.$-actin $)$ treatment $-\left(\mathrm{Ct}_{\text {Target }}-\mathrm{Ct}_{\beta}\right.$-actin $)$ control. Relative expression was normalized and expressed relative to the expression in the control group.

\section{Gut Microbiota}

Total genome DNA from colonic digesta was extracted using QIAamp DNA Stool Mini Kit and DNA concentration and purity was monitored on $1 \%$ agarose gels. The $\mathrm{V} 3-\mathrm{V} 4$ region of the bacterial $16 \mathrm{~S}$ ribosomal RNA gene were amplified by 
TABLE 2 | Primers used for quantitative reverse transcription PCR.

\begin{tabular}{|c|c|c|}
\hline Gene & Accession no. & Sequence $\left(5^{\prime}-3^{\prime}\right)$ \\
\hline$\beta$-actin & XM_0031242803 & $\begin{array}{l}\text { F: CTGCGGCATCCACGAAACT R: } \\
\text { AGGGCCGTGATCTCCTTCTG }\end{array}$ \\
\hline MnSOD & NM_001190422.1 & $\begin{array}{l}\text { F: GAGCTGAAGGGAGAGAAGACAGT } \\
\text { R: GCACTGGTACAGCCTTGTGTAT }\end{array}$ \\
\hline CuZnSOD & NM_214127.2 & $\begin{array}{l}\text { F: CTGGACAAATCTGAGCCCTAAC R: } \\
\text { GACGGATACAGCGGTCAACT }\end{array}$ \\
\hline GPX1 & NM_214201 & $\begin{array}{l}\text { F: CGATGCCACTGCCCTCAT R: } \\
\text { GGCCCACCAGGAACTTCTC }\end{array}$ \\
\hline $\mathrm{GP} \times 4$ & NM_214407 & $\begin{array}{l}\text { F: GCTGGCTACAACGTCAAATTTG R: } \\
\text { TCCCCTTGGGCTGGACTT }\end{array}$ \\
\hline CAT1 & NM_001012613 & $\begin{array}{l}\text { F: GGCAAGACCAAACTCTCCTTC R: } \\
\text { AGCCTATCAGCATCCACACTG }\end{array}$ \\
\hline
\end{tabular}

F, forward; $R$, reverse.

using specific primer. Amplicons were extracted from 2\% agarose gels and purified using the GeneJET gel extraction kit (Thermo Scientific) according to the manufacturer's instructions. After quantified and purified, amplicons were sequenced. The sequences were analyzed and assigned to operational taxonomic units (OTUs; 97\% identity). Alpha diversity was analyzed using QIIME (Version 1.7.0), which included calculation of ACE, Chao 1, Shannon, and Simpson indices. Beta diversity was analyzed using principal component analysis (PCA) and unweighted Unifrac cluster tree.

\section{Statistical Analysis}

All data were analyzed using the one-way analysis of variance (ANOVA) followed by Duncan's multiple comparisons (SPSS 22.0 software). In this study, comparisons were made between different experimental groups at the same time and no comparisons between different treatment times were made. Data are expressed as the mean \pm SEM. Probability values $\leq 0.05$ were taken to indicate statistical significance.

\section{RESULTS}

\section{D-Galactose Decreased Body Weight and Average Daily Feed Intake in Piglets}

To investigate whether D-galactose could induce chronic oxidative stress in piglets, we determined the growth performance and organ index of piglets fed the basal diet with different levels of D-galactose. The results showed that 10 and $20 \mathrm{~g} / \mathrm{kg} \mathrm{BW} \mathrm{D-}$ galactose significantly reduced $\mathrm{BW}, \mathrm{ADG}$, and $\mathrm{ADFI}$ from the first week to the end as compared to the control and $5 \mathrm{~g} / \mathrm{kg} \mathrm{BW}$ D-galactose $(P<0.05)$ (Figures 1A-C). Notably, $10 \mathrm{~g} / \mathrm{kg}$ BW Dgalactose administration markedly decreased the heart/BW ratio at the third week $(P<0.05)$ (Figure 1D), while D-galactose failed to affect the liver/BW, spleen/BW, and kidney/BW ratio $(P>0.05)$ (Figures 1E-G).

\section{D-Galactose Had a Negative Effect Jejunum and lleum Morphology in Piglets}

In the jejunum, although D-galactose have no significant effects on the villus height, crypt depth, and villus height/crypt depth $(P>0.05)$ (Figures $2 \mathrm{~A}-\mathbf{C}, \mathbf{I})$, the villus surface area of $20 \mathrm{~g} / \mathrm{kg} \mathrm{BW}$ $\mathrm{D}$-galactose group was significantly lower than the other groups $(P<0.05)$ (Figure 2D). In the ileum, $5 \mathrm{~g} / \mathrm{kg} \mathrm{BW} \mathrm{D-galactose}$ slightly increased villus height, whereas $20 \mathrm{~g} / \mathrm{kg} \mathrm{BW} \mathrm{D}$-galactose markedly reduced the villus height compared to the control group

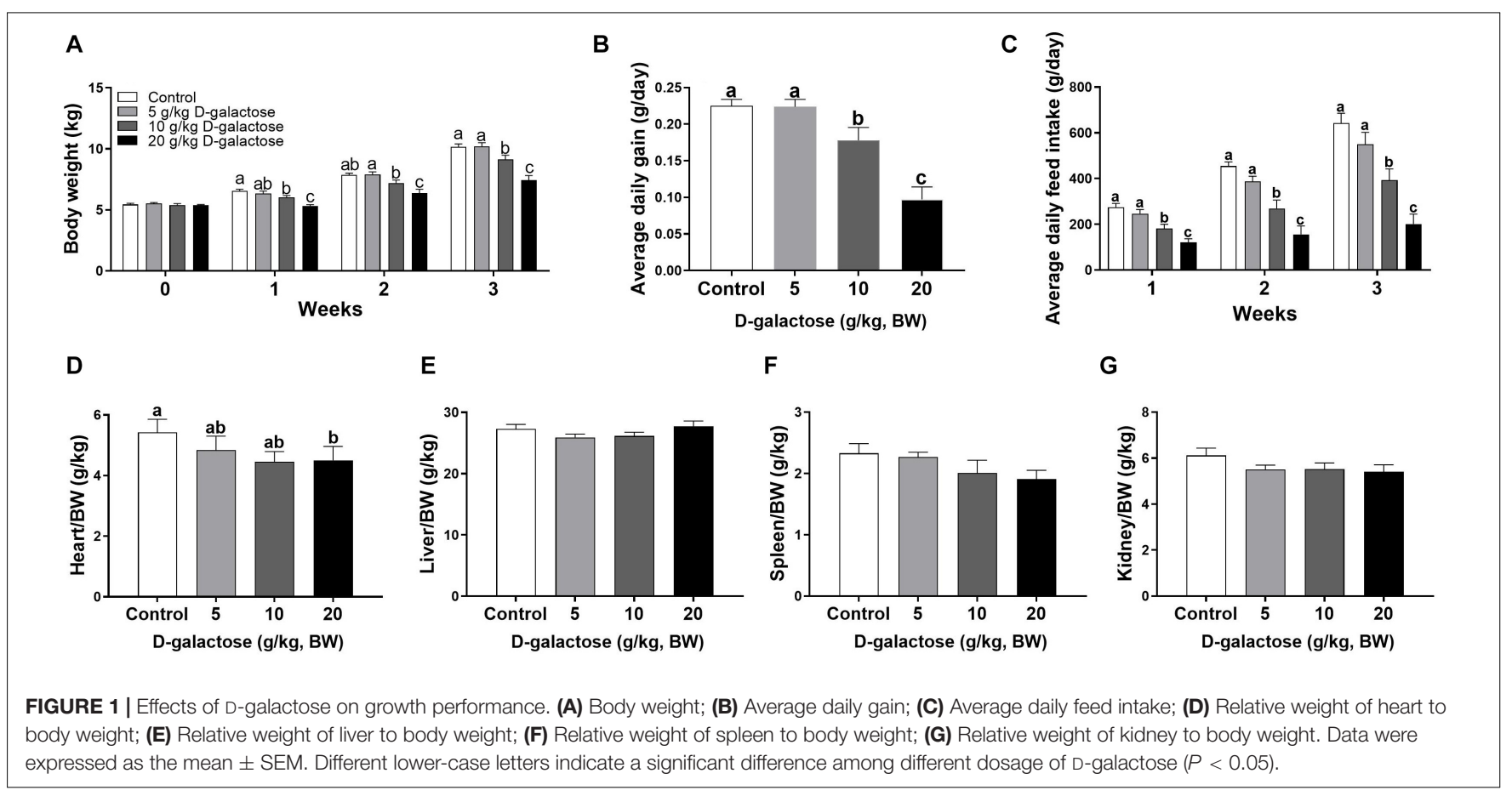


A

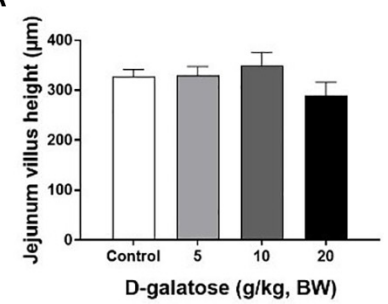

E

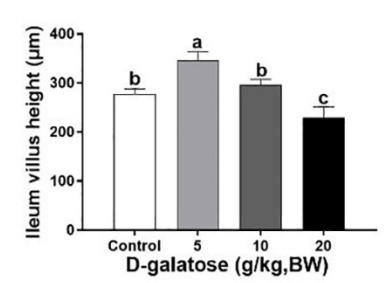

B

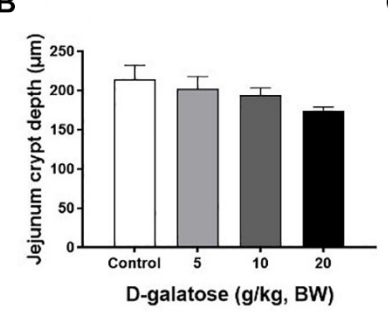

F

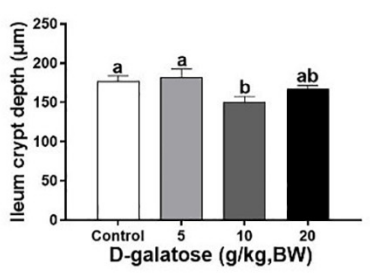

C

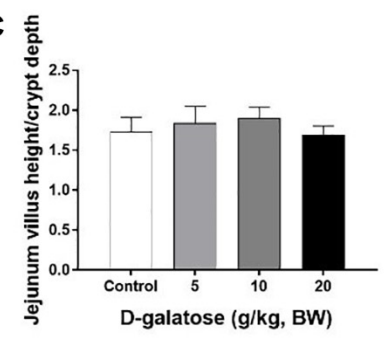

G

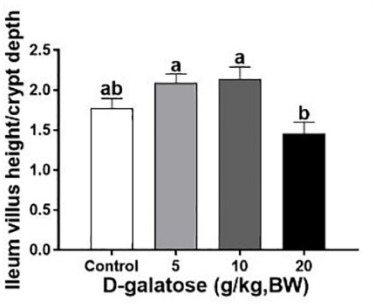

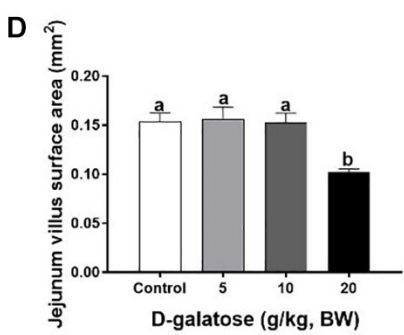

$\mathrm{H}$

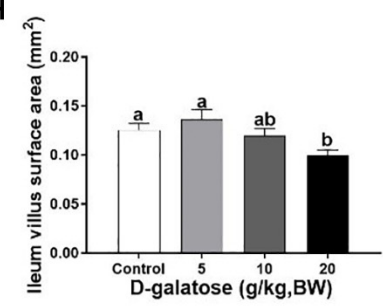

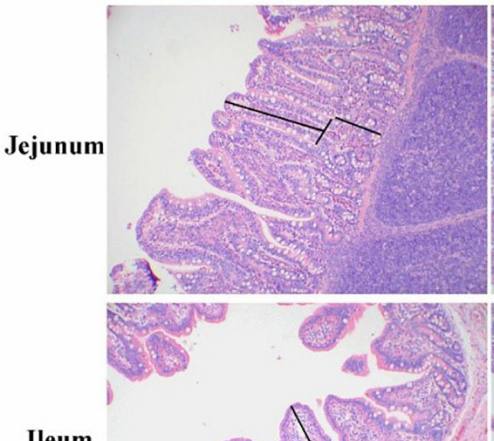

Ileum

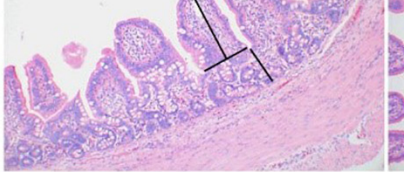

Control

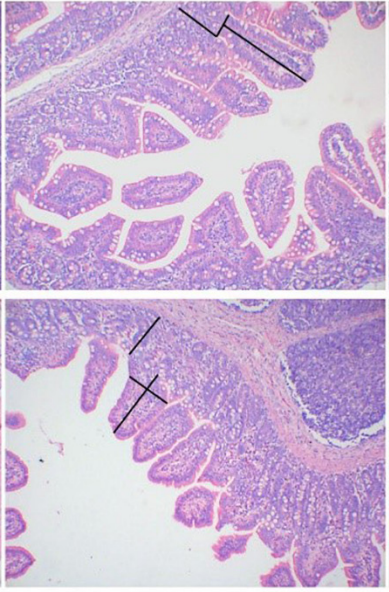

$5 \mathrm{~g} / \mathrm{kg}$ D-galactose

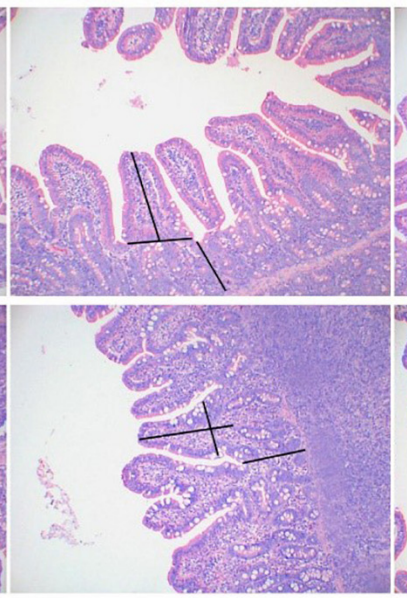

$10 \mathrm{~g} / \mathrm{kg} \mathrm{D}$-galactose

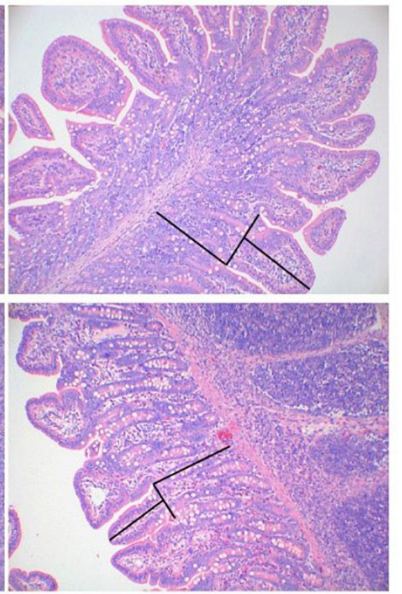

$20 \mathrm{~g} / \mathrm{kg}$ D-galactose

FIGURE 2 | Effects of D-galactose on jejunal and ileal morphology. (A) Jejunum villus height; (B) Jejunum crypt depth; (C) Jejunum villus height/crypt depth; (D) Jejunum villus surface area; (E) lleum villus height; (F) lleum crypt depth; (G) lleum villus height/crypt depth; (H) lleum villus surface area; (I) Representative images of HE staining in the jejunum and ileum. Data were expressed as the mean $\pm \mathrm{SEM}$. Different lower-case letters indicate a significant difference among different dosage of $\mathrm{D}$-galactose $(P<0.05)$.

$(P<0.05)$ (Figure 2E). Meanwhile, $10 \mathrm{~g} / \mathrm{kg} \mathrm{BW}$ D-galactose decreased the crypt depth $(P<0.05)$ (Figure 2 F). D-galactose had no significant effects on the villus height/crypt depth $(P>0.05)$ (Figures 2G,I). The villus surface area was significantly lower in the $20 \mathrm{~g} / \mathrm{kg} \mathrm{BW} \mathrm{D-galactose} \mathrm{group} \mathrm{than} \mathrm{the} \mathrm{control} \mathrm{group}$ $(P<0.05)($ Figure 2H)

\section{D-Galactose Influenced Serum Biochemical Parameters}

At the first week, $20 \mathrm{~g} / \mathrm{kg} \mathrm{BW} \mathrm{D}$-galactose significantly increased the level of TP $(P<0.05)$ (Figure 3A), whereas $20 \mathrm{~g} / \mathrm{kg}$ BW Dgalactose markedly decreased the level of ALB at the third week $(P<0.05)$ (Figure 3B). The level of ALT was significantly higher in the $20 \mathrm{~g} / \mathrm{kg} \mathrm{BW} \mathrm{D-galactose} \mathrm{group} \mathrm{than} \mathrm{that} \mathrm{in} \mathrm{the} \mathrm{control}$ and $5 \mathrm{~g} / \mathrm{kg} \mathrm{BW} \mathrm{D-galactose} \mathrm{groups}(P<0.05)$ at the first 2 weeks (Figure 3C). $5 \mathrm{~g} / \mathrm{kg} \mathrm{BW} \mathrm{D-galactose} \mathrm{markedly} \mathrm{increased} \mathrm{the} \mathrm{level}$ of AST compared to the other groups $(P<0.05)$ (Figure 3D). However, D-galactose had no effect on the levels of serum ALP, CHOL, HDL, and LDL in piglets $(P>0.05)$ (Figures 3E-H).

\section{D-Galactose Induced an Imbalance in Serum Amino Acids of Piglets}

At the first week, compared to the control group, $5 \mathrm{~g} / \mathrm{kg} \mathrm{BW} \mathrm{D-}$ galactose significantly decreased the concentration of His, Leu, and Asp and increased the Trp content in serum $(P<0.05)$ (Figures 4, 5). The concentration of Val, Leu, His, Phe, and Tyr are significantly lower in $10 \mathrm{~g} / \mathrm{kg} \mathrm{BW} \mathrm{D}$-galactose group than that in the control group $(P<0.05)$ (Figures 4, 5). $20 \mathrm{~g} / \mathrm{kg} \mathrm{BW} \mathrm{D-}$ galactose markedly increased the concentration of Arg and Thr in serum $(P<0.05)$ (Figure 4).

At the second week, compared to the control group, $5 \mathrm{~g} / \mathrm{kg}$ BW D-galactose significantly decreased the concentration of 


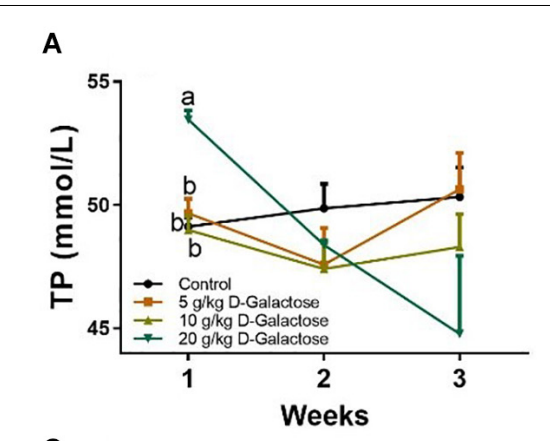

c

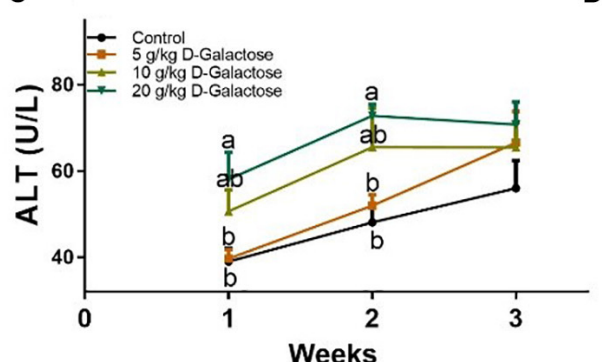

$\mathbf{F}$

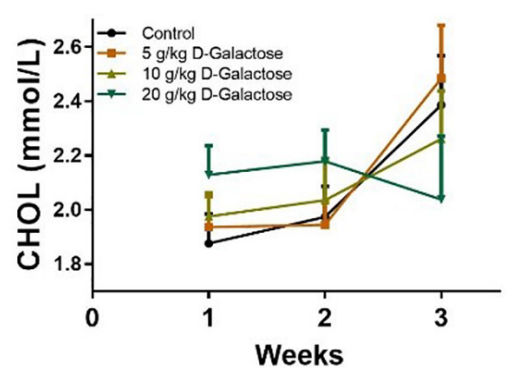

B

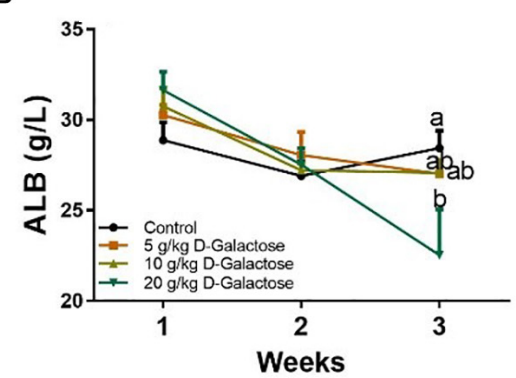

D

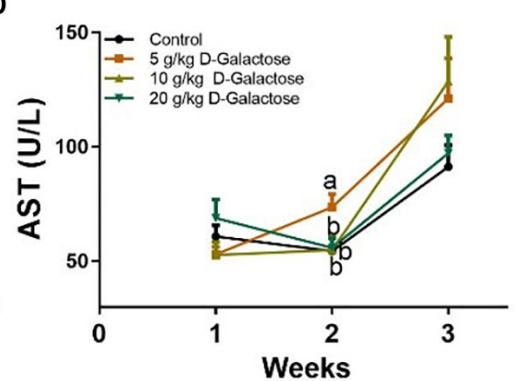

G

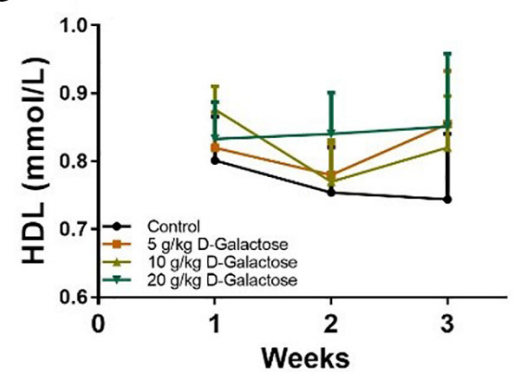

E

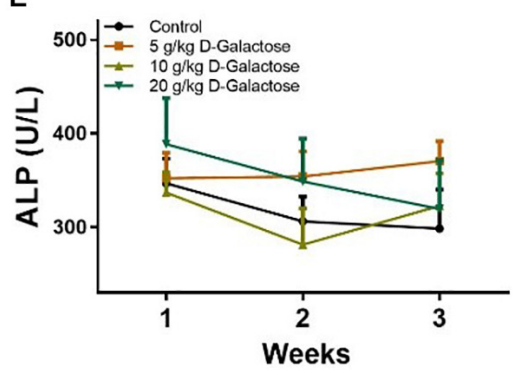

H

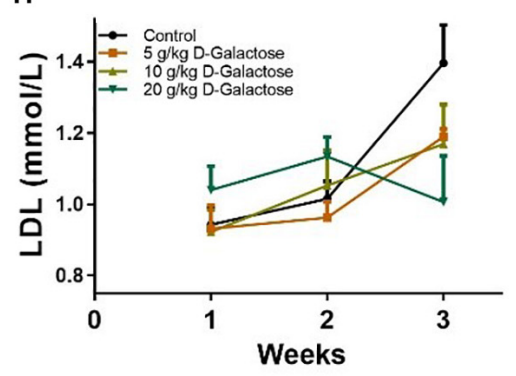

FIGURE 3 | Effects of D-galactose on serum biochemical parameters. (A) TP; (B) ALB; (C) ALT; (D) AST; (E) ALP; (F) CHOL; (G) HDL; (H) LDL. Data were expressed as the mean \pm SEM. Different lower-case letters indicate a significant difference among different dosage of $\mathrm{D}$-galactose $(P<0.05)$.

Cys, while $20 \mathrm{~g} / \mathrm{kg}$ BW D-galactose significantly decreased the abundance of Ile $(P<0.05)$ (Figures 6, 7).

At the third week, the concentration of Ile, Leu, and Ala in the $5 \mathrm{~g} / \mathrm{kg} \mathrm{BW} \mathrm{D}$-galactose group is significantly higher than that in the control group $(P<0.05)$ (Figures 8, 9). $10 \mathrm{~g} / \mathrm{kg} \mathrm{BW} \mathrm{D-}$ galactose markedly increased the abundance of Ala and $20 \mathrm{~g} / \mathrm{kg}$ BW D-galactose significantly increased the concentration of Arg, Thr, Pro, Ala, and Tyr in serum $(P<0.05)$ (Figures 8, 9).

\section{D-Galactose Affected Serum Antioxidant Enzyme Activities and MDA Level in Piglets}

To confirm whether the model of D-galactose induced piglet chronic oxidative stress was successful, serum antioxidant enzymes (GSH-Px, SOD, and CAT) activities and MDA level in piglets were measured. Although the MDA level at the first week were not changed among these groups, $10 \mathrm{~g} / \mathrm{kg} \mathrm{BW}$ D-galactose significantly increased the level of MDA $(P<0.05)$ at the second week (Figure 10A). $5 \mathrm{~g} / \mathrm{kg}$ BW D-galactose significantly increased the level of MDA compared to the control and $20 \mathrm{~g} / \mathrm{kg} \mathrm{BW}$ D-galactose groups
$(P<0.05)$ at the third week (Figure 10A). Meanwhile, $10 \mathrm{~g} / \mathrm{kg} \mathrm{D}$-galactose $(5.48 \pm 0.06)$ tend to increase the MDA concentration compared to the group $(6.29 \pm 0.46)$ at the third week, although the difference was not significant $(P>0.05)$ (Figure 10A).

At the first week, the activity of GSH-Px markedly increased in response to $5 \mathrm{~g} / \mathrm{kg} \mathrm{BW} \mathrm{D-galactose,} \mathrm{whereas} 10$ and $20 \mathrm{~g} / \mathrm{kg}$ BW D-galactose significantly decrease the activity of GSH-Px $(P<0.05)$ (Figure 10B). However, 10 and $20 \mathrm{~g} / \mathrm{kg} \mathrm{BW} \mathrm{D-}$ galactose significantly increased the activity of GSH-Px at the second week compared to the control and $5 \mathrm{~g} / \mathrm{kg}$ BW D-galactose groups $(P<0.05)$ (Figure 10B). At the third week, $10 \mathrm{~g} / \mathrm{kg} \mathrm{BW}$ $\mathrm{D}$-galactose markedly increased the activity of GSH-Px $(P<0.05)$ (Figure 10B). In addition, $5 \mathrm{~g} / \mathrm{kg} \mathrm{BW} \mathrm{D}$-galactose significantly reduced the activity of CAT when compared that of the 10 and $20 \mathrm{~g} / \mathrm{kg} \mathrm{BW} \mathrm{D}$-galactose groups $(P<0.05)$ at the first week (Figure 10C). $5 \mathrm{~g} / \mathrm{kg}$ BW D-galactose markedly increased the activity of CAT compared to the other groups at the third week $(P<0.05)$ (Figure 10C). However, administration of D-galactose failed to affect the activity of SOD from the first week to the end $(P>0.05)$ (Figure 10D). 

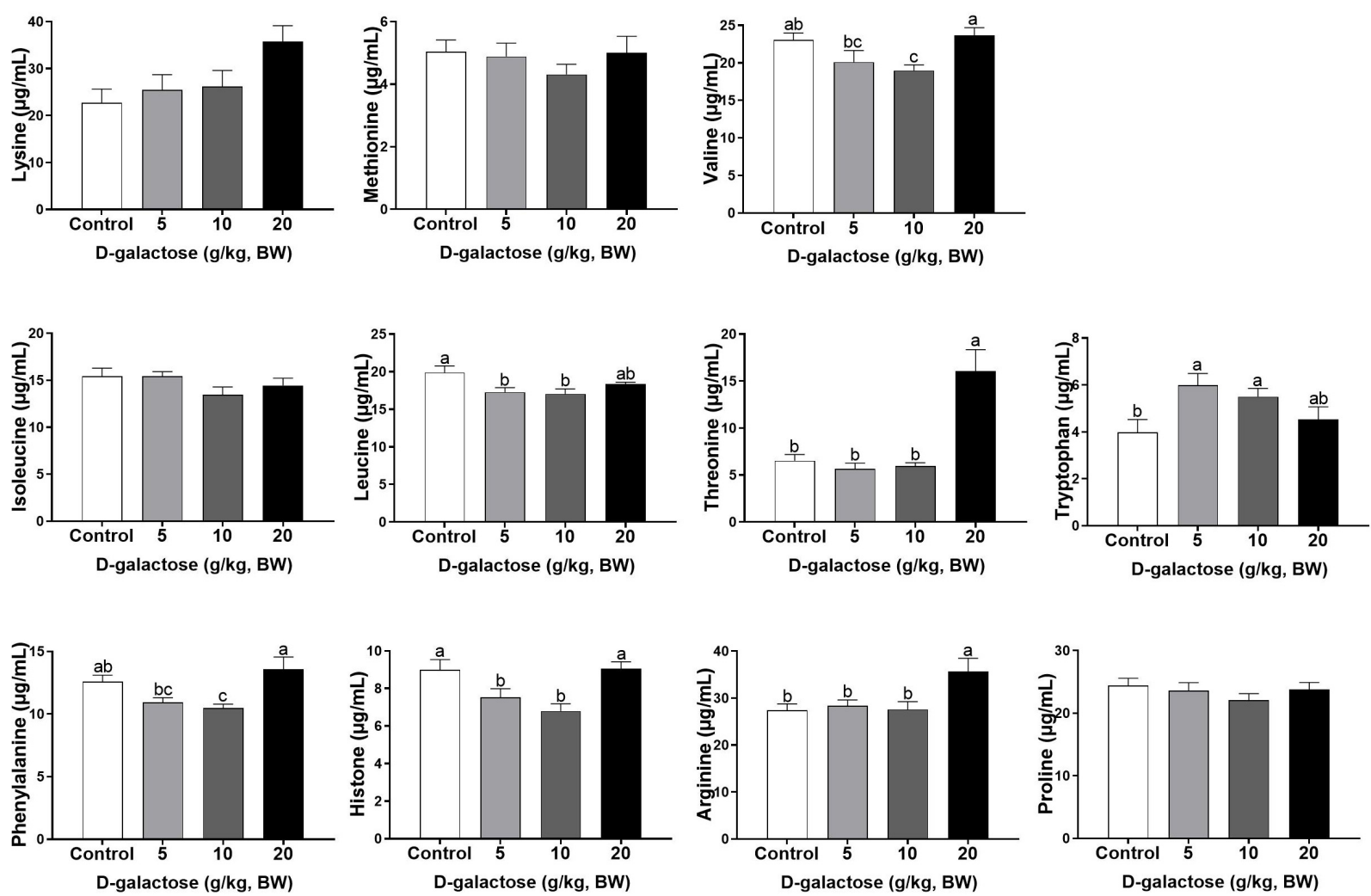

FIGURE 4 | Effects of D-galactose on essential amino acids in the serum at the first week. Data were expressed as the mean \pm SEM. Different lower-case letters indicate a significant difference among different dosage of D-galactose $(P<0.05)$.
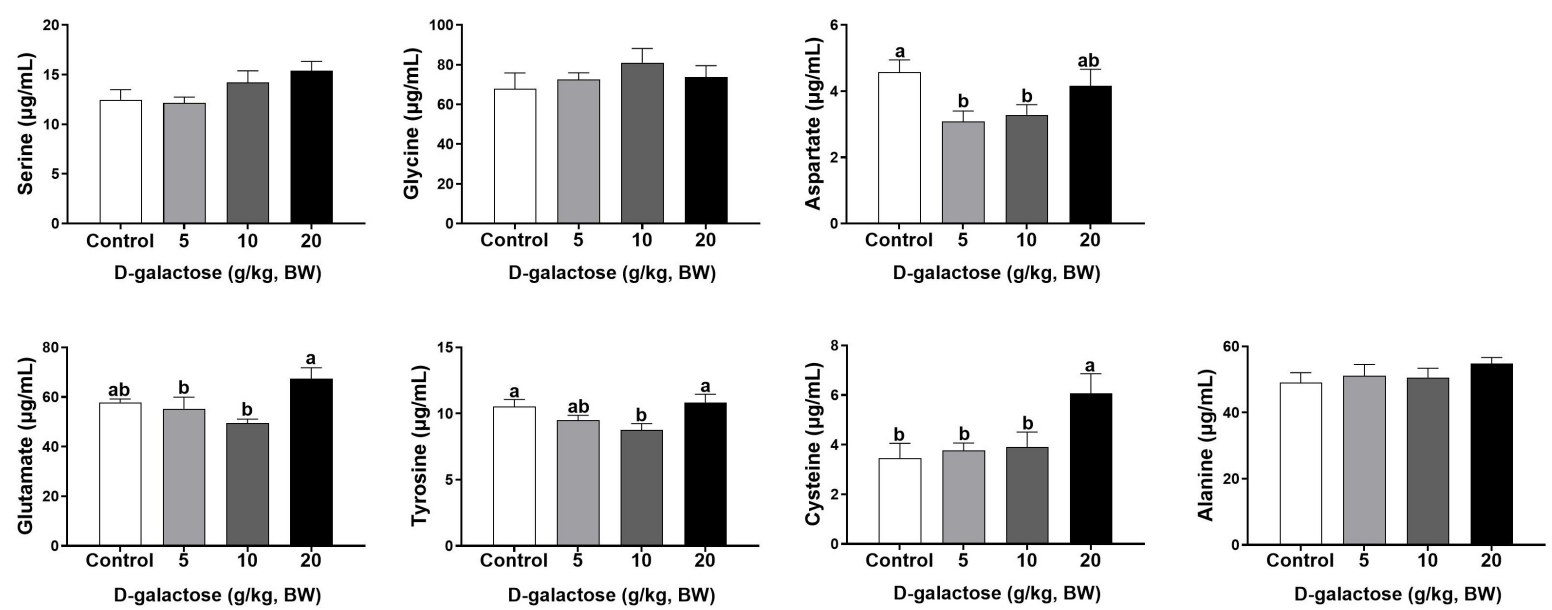

FIGURE 5 | Effects of D-galactose on non-essential amino acids in the serum at the first week. Data were expressed as the mean \pm SEM. Different lower-case letters indicate a significant difference among different dosage of $\mathrm{D}$-galactose $(P<0.05)$.

\section{D-Galactose Influenced the mRNA Expressions of GPx1, CAT1, and MnSOD in Jejunum and lleum of Piglets}

D-galactose treatment had no significant effects on the jejunal mRNA expression of MnSOD, CuZnSOD, and Gpx4 $(p>0.05)$
(Figures 11A,B,D). $5 \mathrm{~g} / \mathrm{kg}$ BW D-galactose significantly increased the jejunal mRNA expression of GPx1 compared with the control group $(P<0.05)$ (Figure 11C). $10 \mathrm{~g} / \mathrm{kg} \mathrm{BW}$ D-galactose increased the jejunal mRNA expression of CAT1 $(P<0.05)$ (Figure 11E). In the ileum, the mRNA expression of $M n S O D$ was significantly higher in the $10 \mathrm{~g} / \mathrm{kg} \mathrm{BW}$ D-galactose than that in 

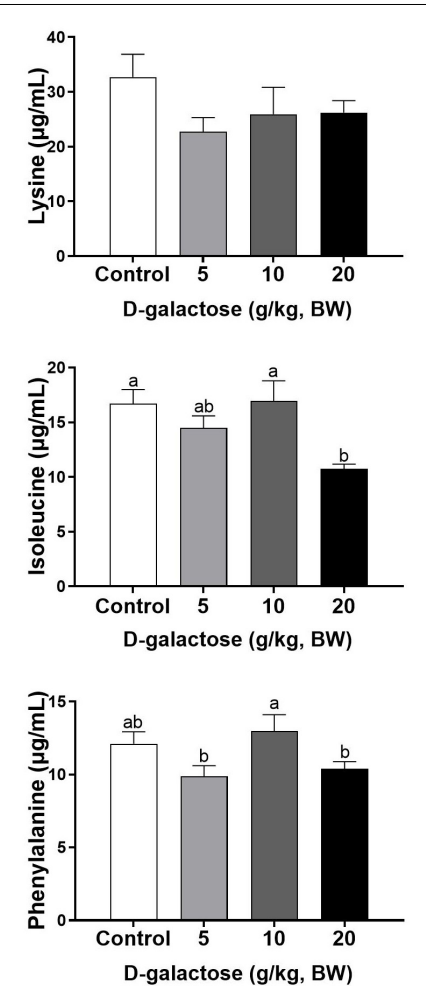
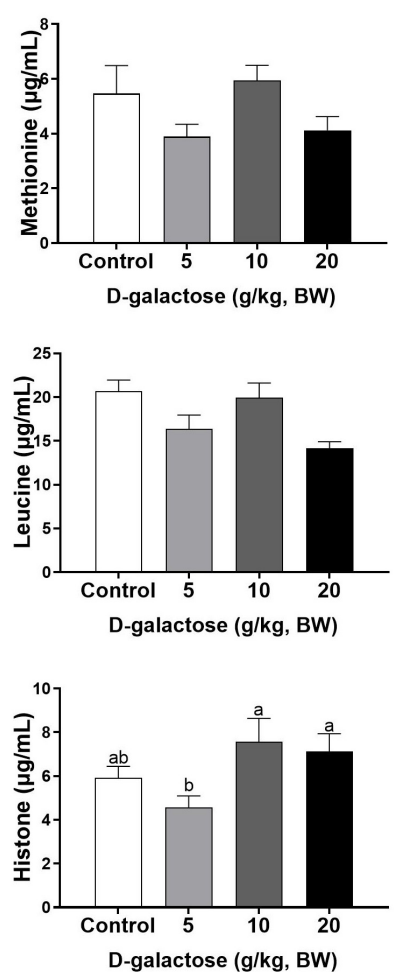
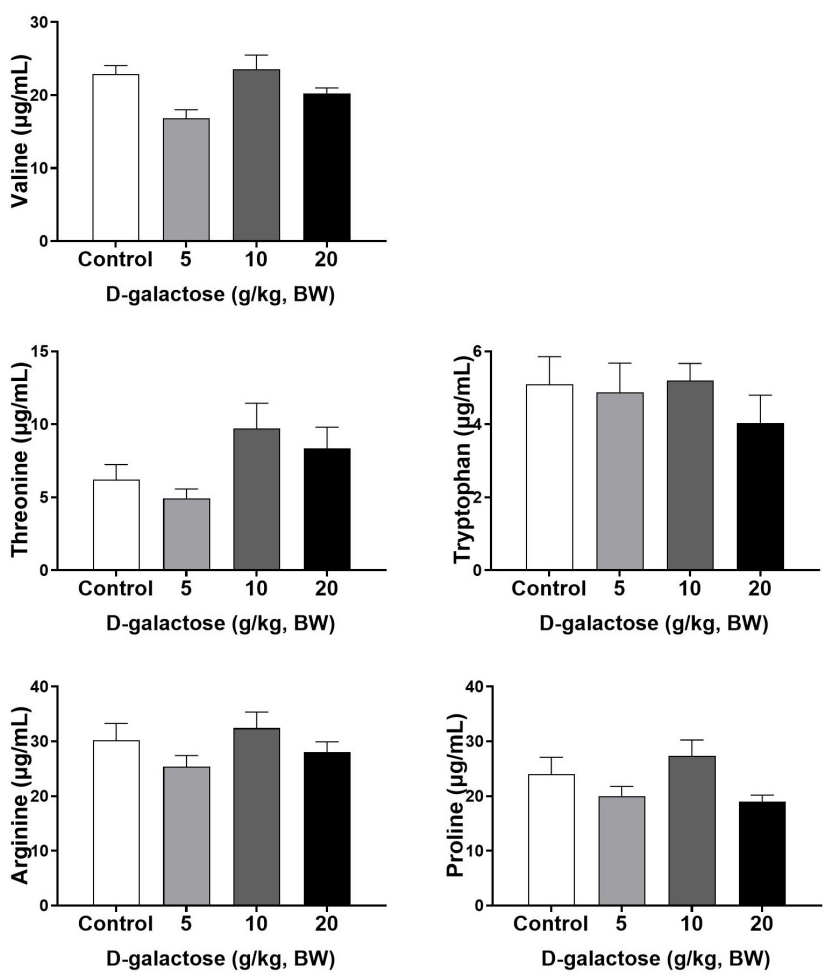

FIGURE 6 | Effects of D-galactose on essential amino acids in the serum at the second week. Data were expressed as the mean \pm SEM. Different lower-case letters indicate a significant difference among different dosage of D-galactose $(P<0.05)$.
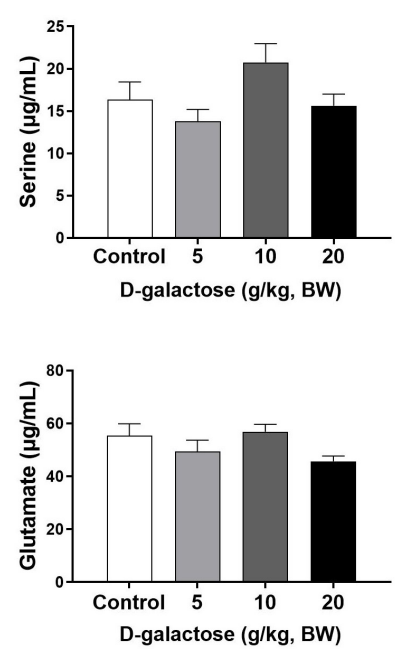
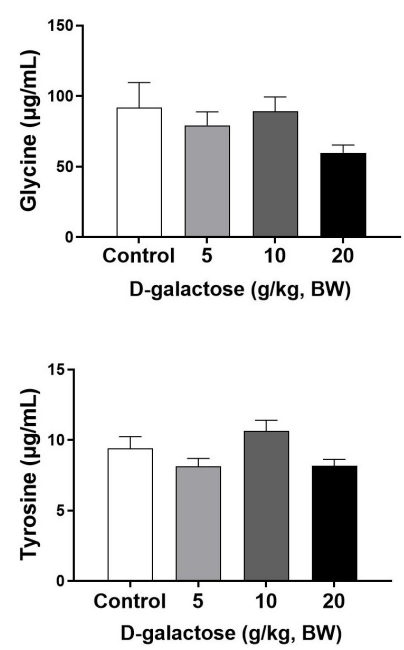
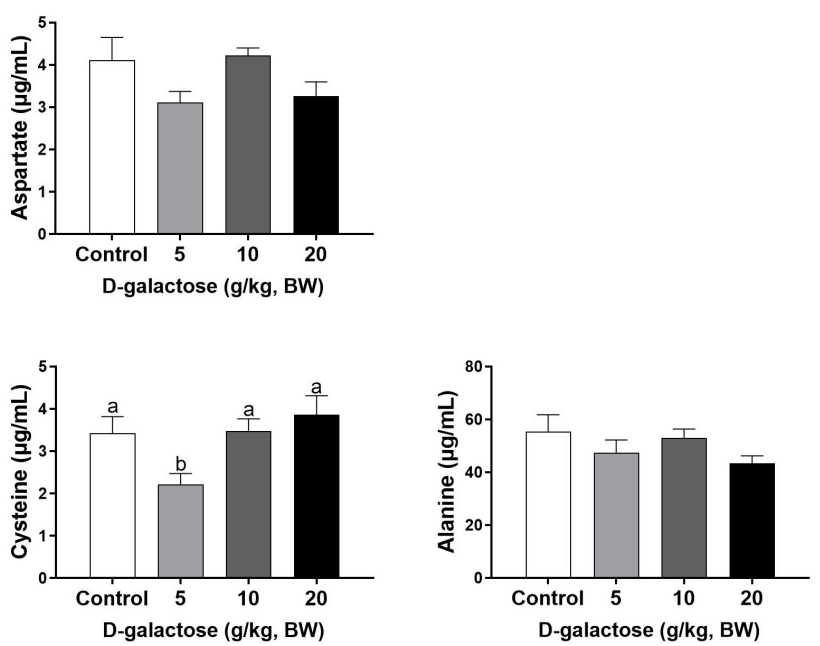

FIGURE 7 | Effects of D-galactose on non-essential amino acids in the serum at the second week. Data were expressed as the mean \pm SEM. Different lower-case letters indicate a significant difference among different dosage of $D$-galactose $(P<0.05)$.

the other groups $(P<0.05)$ (Figure 11F). Administration of Dgalactose markedly reduced the expression of ileal GPX1 $(5,10$, and $20 \mathrm{~g} / \mathrm{kg} \mathrm{BW} \mathrm{D-galactose)} \mathrm{and} \mathrm{CAT1} \mathrm{(5} \mathrm{and} 20 \mathrm{~g} / \mathrm{kg}$ BW D-galactose) $(P<0.05)$ (Figures $11 \mathbf{H}, \mathbf{J})$. D-galactose failed to affect the mRNA expression of CuZnSOD and Gpx4 $(p>0.05)$ (Figures 11G,I).

\section{D-Galactose Influenced Colonic Microbiota in Piglets}

The colonic microbiota was analyzed by sequencing V3 + V4 regions of $16 \mathrm{~S}$ rRNA genes and an average of 72,951.48 raw reads were generated from each sample. After removing the low-quality sequences, an average of $68,692.55$ clean tags were 

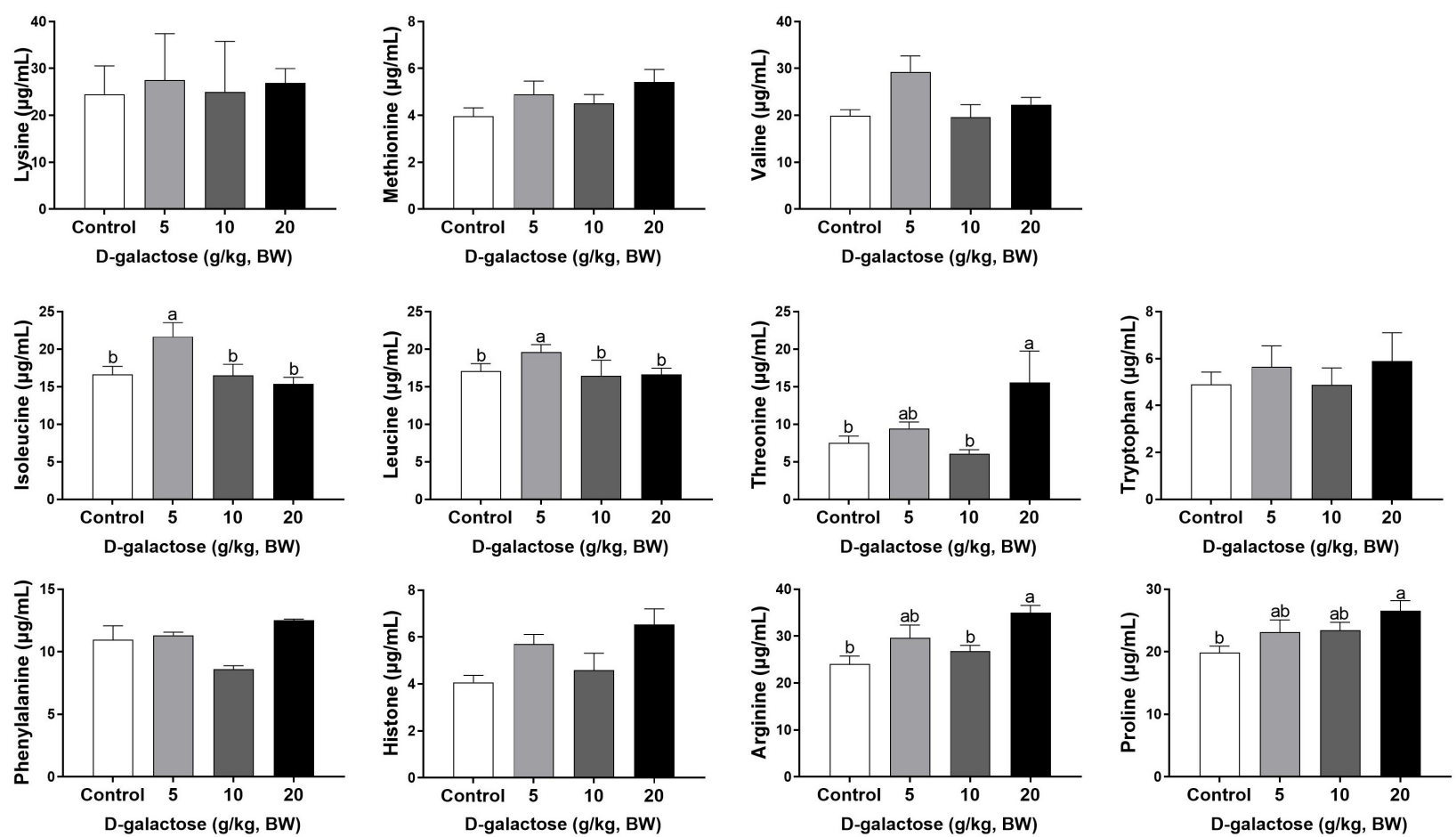

FIGURE 8 | Effects of D-galactose on essential amino acids in the serum at the third week. Data were expressed as the mean \pm SEM. Different lower-case letters indicate a significant difference among different dosage of D-galactose $(P<0.05)$.
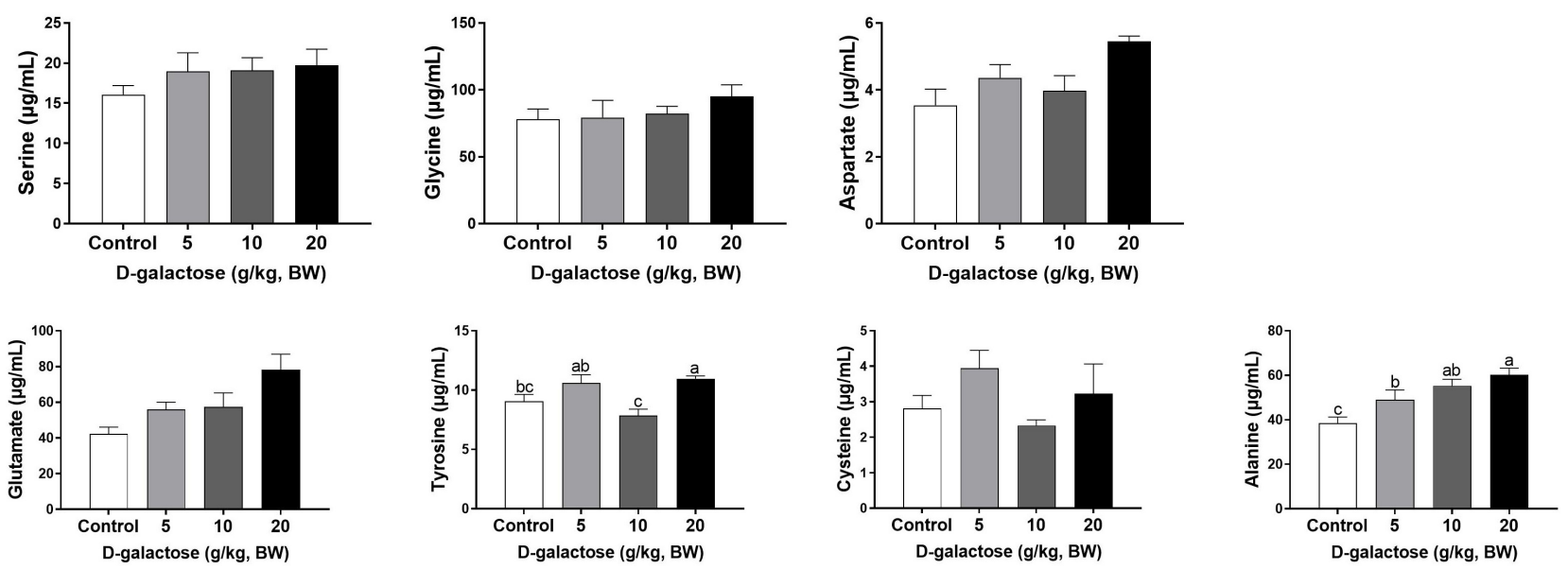

FIGURE 9 | Effects of D-galactose on non-essential amino acids in the serum at the third week. Data were expressed as the mean \pm SEM. Different lower-case letters indicate a significant difference among different dosage of $\mathrm{D}$-galactose $(P<0.05)$.

clustered into OTUs. To identify the microbial biodiversity, the reads were clustered into operation taxonomic units (OTUs) basing on $97 \%$ identity.

ACE and Chao 1 indexes were examined for the community richness and Shannon and Simpson were examined for the community diversity. As shown in Figures 12A-C, compared to the control and $5 \mathrm{~g} / \mathrm{kg}$ BW D-galactose groups, 10 and $20 \mathrm{~g} / \mathrm{kg}$ BW D-galactose significantly decreased the ACE, Chao 1 and
Shannon indexes $(P<0.05)$. Meanwhile, $20 \mathrm{~g} / \mathrm{kg}$ BW D-galactose also significantly decreased the Simpson index when compared to the other groups $(P<0.05)$ (Figure 12D).

To further understand the microbial composition between different groups, we evaluated beta-diversity by using Principal Component Analysis (PCA) and unweighted Unifrac cluster tree based on UPGMA. The results showed that the microbial community structure in 10 and $20 \mathrm{~g} / \mathrm{kg} \mathrm{BW} \mathrm{D-galactose} \mathrm{groups}$ 

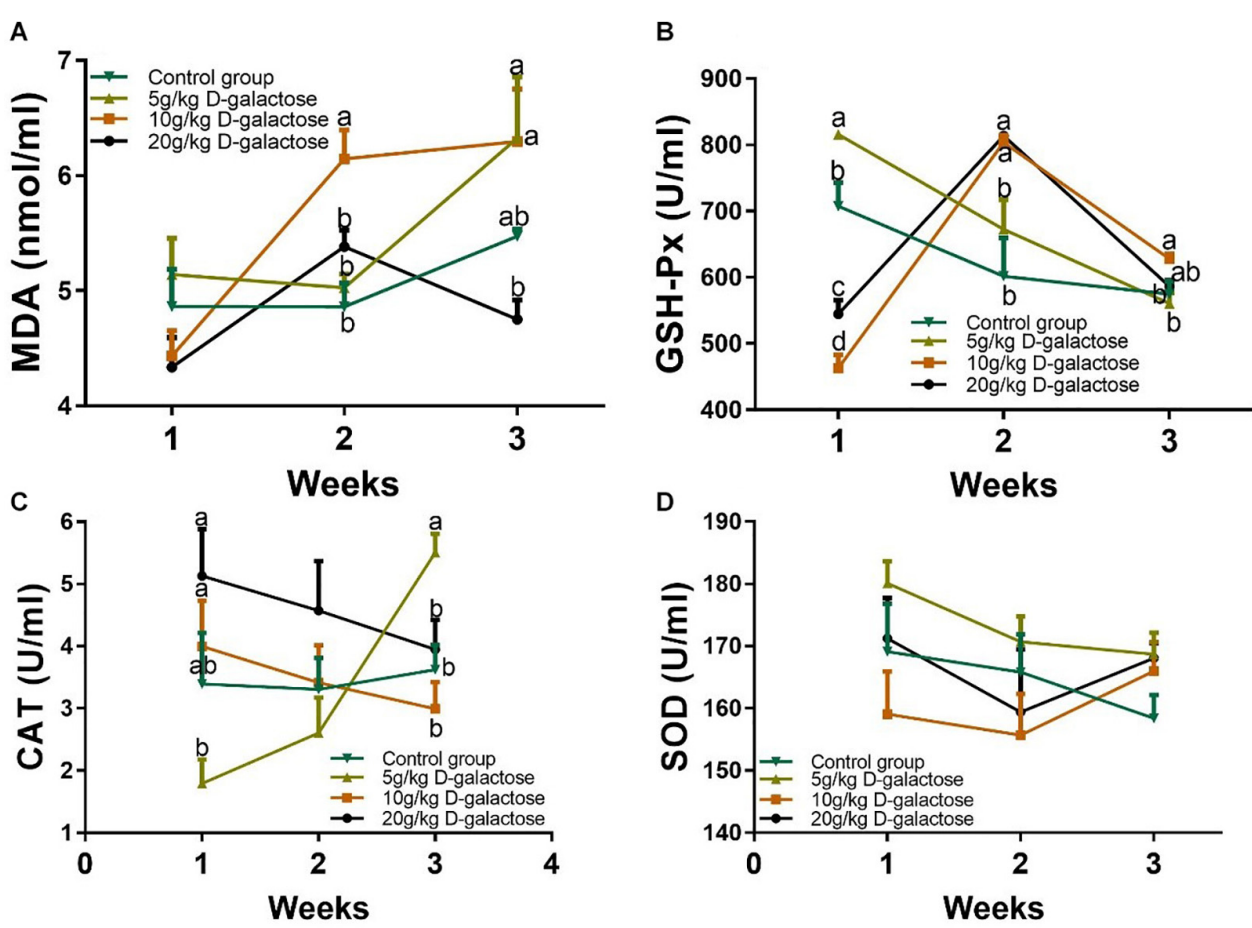

FIGURE 10 | Effects of D-galactose on the level of MDA and activities of antioxidant enzymes. (A) MDA; (B) GSH-Px; (C) CAT; (D) SOD. Data were expressed as the mean \pm SEM. Different lower-case letters indicate a significant difference among different dosage of $D$-galactose $(P<0.05)$.
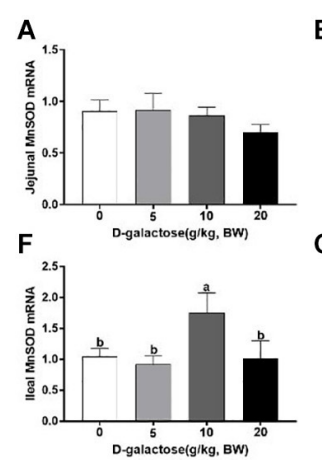

B
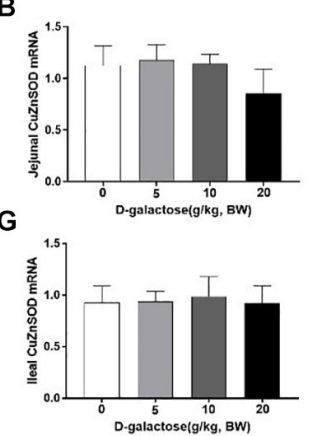

C
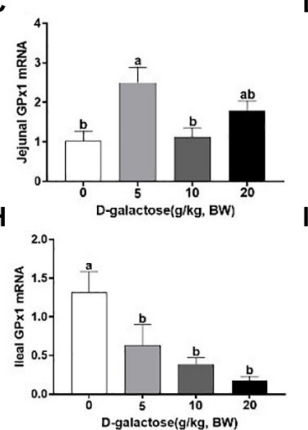

D

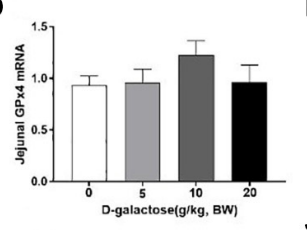

E

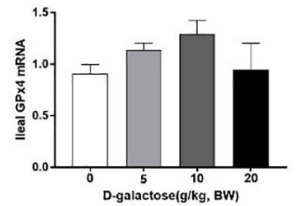

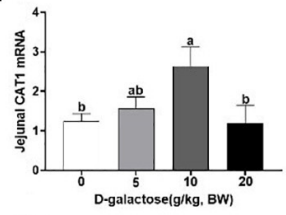

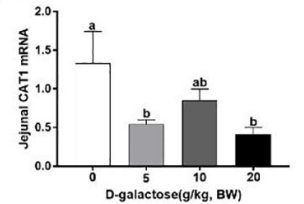

FIGURE 11 | Effects of D-galactose on intestinal expressions of MnSOD, CuZnSOD, GPx1, GPx4, and CAT1. (A-E) mRNA abundances of MnSOD, CuZnSOD, GPx1, GPx4, and CAT1 in the jejunum; (F-J) mRNA abundances of MnSOD, CuZnSOD, GPx1, GPx4, and CAT1 in the ileum. Data were expressed as the mean \pm SEN. Different lower-case letters indicate a significant difference among different dosage of $d$-galactose $(P<0.05)$.

differed significantly from that in control and $5 \mathrm{~g} / \mathrm{kg} \mathrm{BW} \mathrm{D-}$ galactose groups (Figures 12E,F).

The overall microbial composition in the groups differed at the phylum, class, order, and family levels. As shown in Figures 13A,B, at the phylum level, D-galactose (10 and $20 \mathrm{~g} / \mathrm{kg} \mathrm{BW}$ ) significantly decreased the relative abundance of Tenericutes $(P<0.05)$, while it had little effect on the relative abundances of these two largest phyla (Firmicutes and Bacteroidetes $)(P>0.05)$. At the class level, compared to control and $5 \mathrm{~g} / \mathrm{kg}$ BW D-galactose, 10 and $20 \mathrm{~g} / \mathrm{kg}$ BW $\mathrm{D}$-galactose significantly increased the relative abundance of
Negativicutes and significantly decreased the relative abundance of Erysipelotrichia $(P<0.05)$ (Figures 13C,D). The relative abundance of Clostridia was significantly lower in $20 \mathrm{~g} / \mathrm{kg}$ BW D-galactose groups than control and $5 \mathrm{~g} / \mathrm{kg}$ BW Dgalactose groups $(P<0.05)$ (Figures 13C,D). The order level analysis demonstrated that the relative abundance of Clostridiales was significantly lower in the $20 \mathrm{~g} / \mathrm{kg} \mathrm{BW} \mathrm{D-}$ galactose group than the control and $5 \mathrm{~g} / \mathrm{kg} \mathrm{BW}$ D-galactose administration groups $(P<0.05)$ (Figures 13E,F). 10 and $20 \mathrm{~g} / \mathrm{kg}$ BW D-galactose significantly decreased the relative abundance of Erysipelotrichales, while significantly increased the relative 


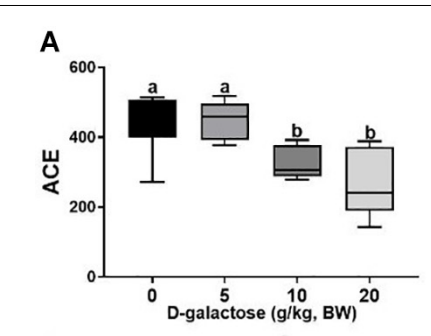

E

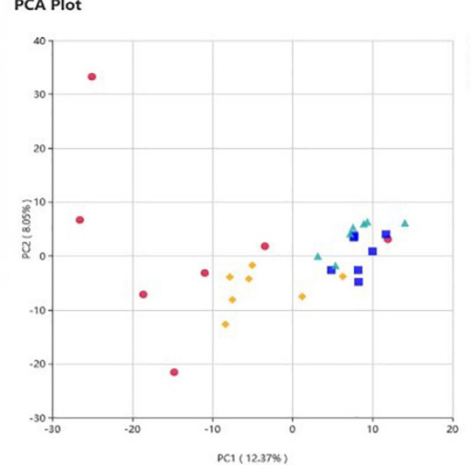

B

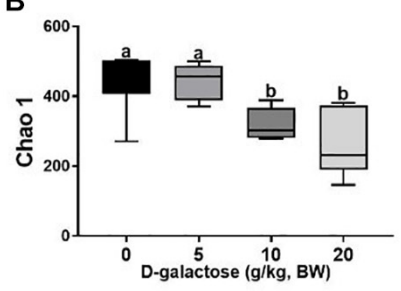

F
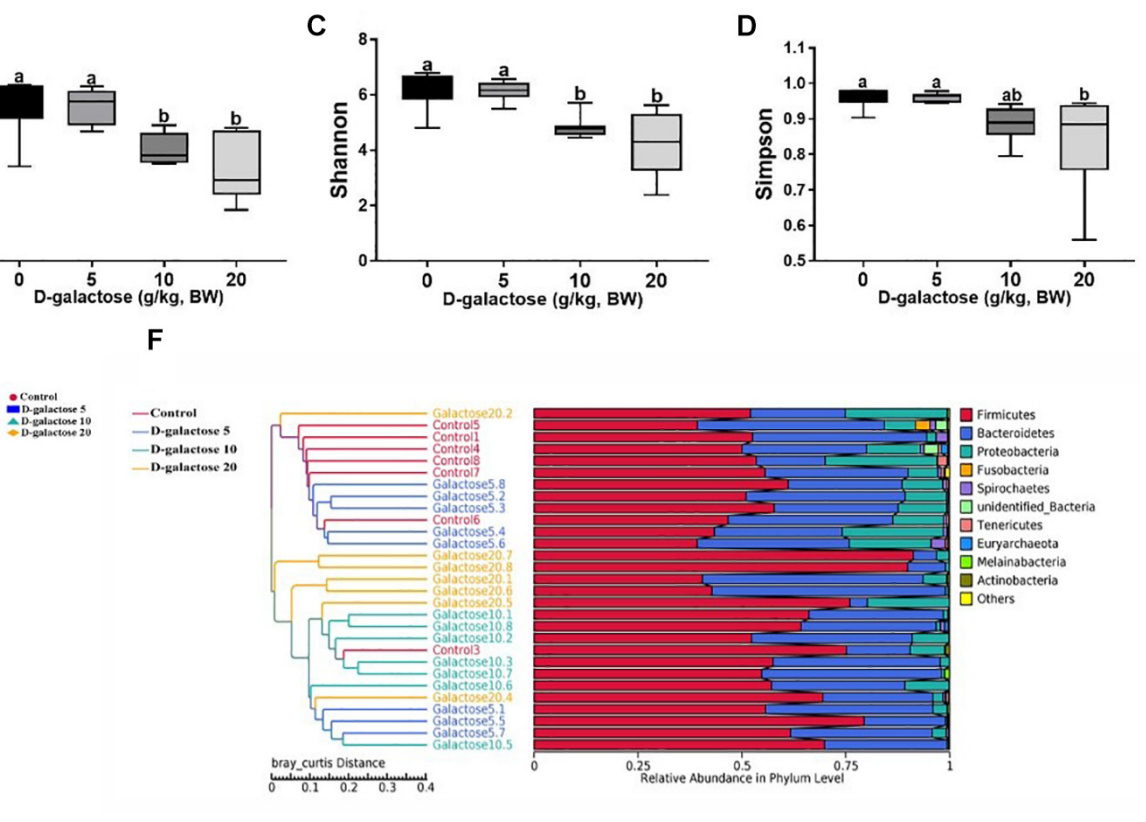

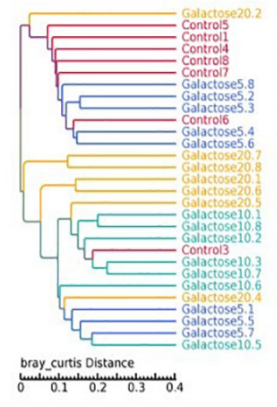

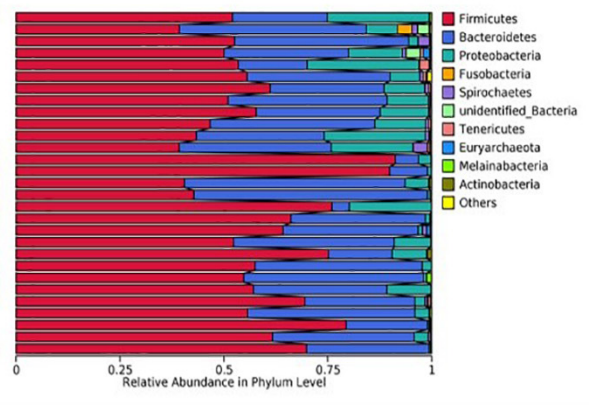

FIGURE 12 | Effects of D-galactose on colonic microbial diversity and unweighted Unifrac distances. (A) ACE index; (B) Chao 1 index; (C) Shannon index; (D) Simpson index; (E) Principal Component Analysis (PCA); (F) Comparison of unweighted Unifrac distances between pairs os samples. Data were expressed as the mean \pm SEN. Different lower-case letters indicate a significant difference among different dosage of D-galactose $(P<0.05)$.

abundance of Selenomonnadales when compared to control and $5 \mathrm{~g} / \mathrm{kg}$ BW D-galactose $(P<0.05)$ (Figures 13E,F). At the family level, 10 and $20 \mathrm{~g} / \mathrm{kg} \mathrm{BW}$ D-galactose significantly increased the relative abundance of Veillonellaceae and significantly decreased the relative abundance of Erysipelotrichaceae when compared to control and $5 \mathrm{~g} / \mathrm{kg}$ BW D-galactose groups $(P<0.05)$ (Figures 13G,H). The relative abundance of Lachnospiraceae were significantly lower in the $20 \mathrm{~g} / \mathrm{kg} \mathrm{BW} \mathrm{D-galactose} \mathrm{than}$ the other groups (control and $5 \mathrm{~g} / \mathrm{kg} \mathrm{BW} \mathrm{D-galactose} \mathrm{groups)}$ $(P<0.05)$ (Figures 13G,H).

\section{DISCUSSION}

It has been reported that D-galactose could be changed into galactitol, which will accumulate in the cell and then generate the excess of ROS, thereby leading to oxidative stress (Zhang X. et al., 2019). Previous studies reported that administration of D-galactose could lower body weight and disrupt antioxidant enzymes in mice, thereby causing chronic oxidative stress (Mo et al., 2018; Zhang X. et al., 2019). Similarly, in the present study we found that 10 and $20 \mathrm{~g} / \mathrm{kg} \mathrm{BW}$ D-galactose decreased BW and ADFI from the first week to the end in piglets. The integrity of intestine is conducive to the absorption of various nutrients and form a protective barrier to defend kinds of stresses. It is known that oxidative stress can cause intestinal injury, such as decreasing villus height and increasing the production of ROS in the small intestine of piglets (Zheng et al., 2017; da Silva et al., 2019). In the present study, our results showed that addition of $20 \mathrm{~g} / \mathrm{kg} \mathrm{BW} \mathrm{D-galactose}$ decreased villus height and villus surface area in ileum of piglets. In view of the above data, we speculated that excessive addition of D-galactose could affect the growth performance in piglets and disrupt ileal morphology. This may be that the accumulation of D-galactose was converted into indigestible galactitol, then which caused to generate amounts of ROS in the body, however, the detailed mechanisms need to be further studied.

Amino acids are essential nutrient which have been required for tissue protein synthesis and other metabolic function in animals. Our previous study has revealed that oxidative stress could cause alterations of serum amino acid levels in piglets (Duan et al., 2016). In this study, consistent with the decreased performance growth, D-galactose administration also changed the concentrations of serum amino acids, such as EAA His, Arg, Trp, Thr, Val, Leu, Phe, and NEAA Tyr, Cys, Asp. Amounting evidence has showed that amino acids involve in modulating oxidative stress. For example, Val and Leu can induce oxidative stress by producing excessive ROS (Zhenyukh et al., 2017), while Arg and Thr can ameliorate oxidative stress (Qiu et al., 2019; Yu et al., 2020). In this study, we found that $10 \mathrm{~g} / \mathrm{kg} \mathrm{BW} \mathrm{D-}$ galactose enhanced the serum concentration of Arg and Thr at the first week, which might protect host against D-galactoseinduced oxidative stress; 5 and $10 \mathrm{~g} / \mathrm{kg}$ BW D-galactose increased serum Val and Leu concentrations at the third week, which might aggravate oxidative stress. Serum ALP, AST, and ALT act as specific indicators of liver injury (Cao et al., 2019). Studies have showed that oxidative stress increased serum and liver AST and ALT levels in piglets (Di Giancamillo et al., 2015; Luo et al., 2016; Pu et al., 2016). Injection of D-galactose increased the serum levels of AST and ALT in mice, which indicated that 


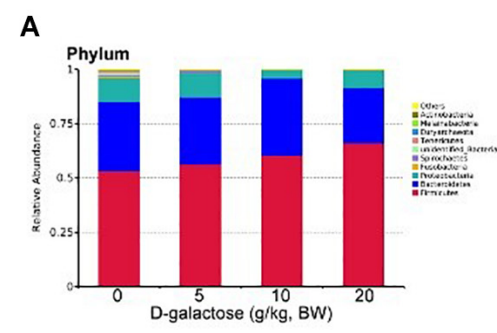

C

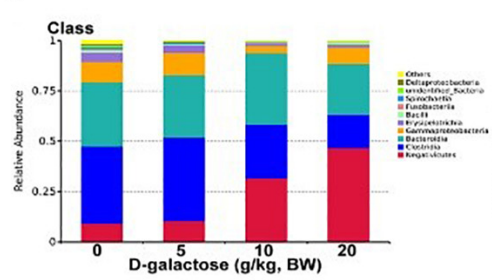

E

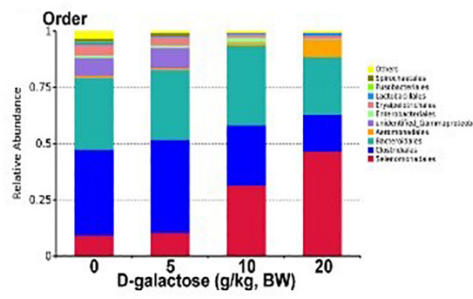

G

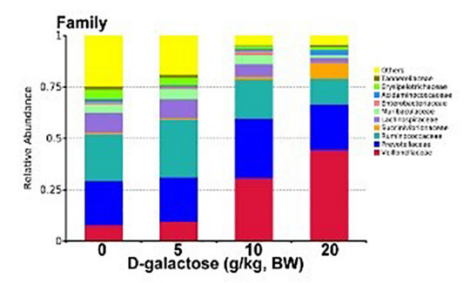

B

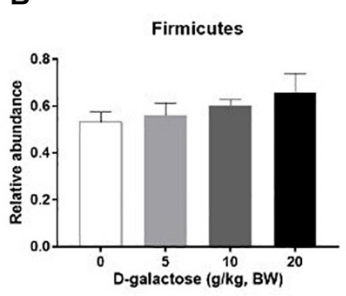

D

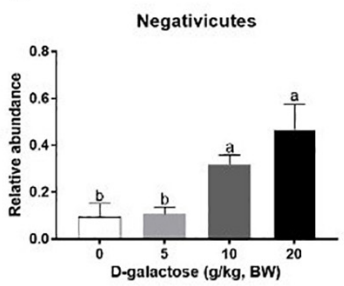

$\mathbf{F}$

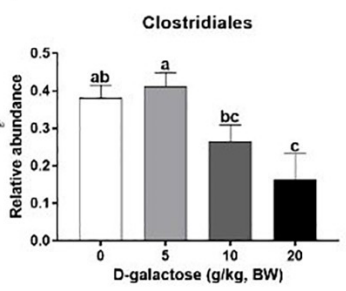

H

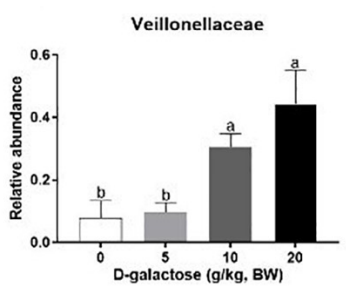

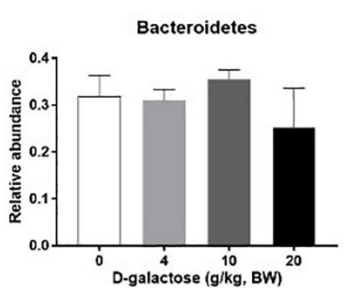
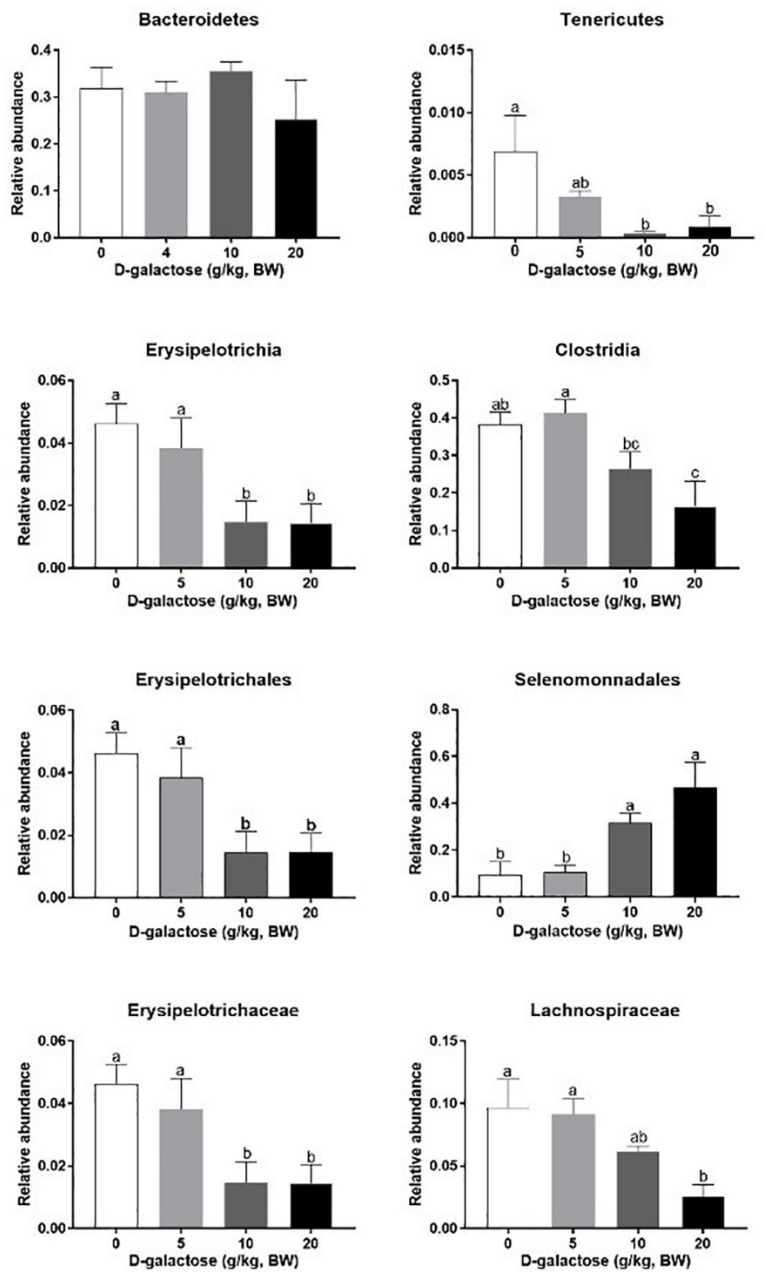

FIGURE 13 | Effects of D-galactose on colonic macterial composition at the phylum, class, order, and family levels. (A,B) Phylum level; (C,D) Class level; (E,F) Order level; $(\mathbf{G}, \mathbf{H})$ Family level. Data were expressed as the mean \pm SEN. Different lower-case letters indicate a significant difference among different dosage of D-galactose $(P<0.05)$.

D-galactose could cause liver injury (Lin et al., 2018). Hepatic AST is present in the cytoplasm and mitochondria and ALT is distributed in the cytoplasm (Feng et al., 2018). The damaged liver release AST and ALT into the circulation system, which enhanced the serum concentrations of AST and ALT (Feng et al., 2018). The present study found that $5 \mathrm{~g} / \mathrm{kg}$ BW D-galactose significantly increased the concentration of serum AST at the second week. Moreover, $20 \mathrm{~g} / \mathrm{kg}$ BW D-galactose significantly increased serum ALT level at the first 2 weeks, while decreased serum ALB level at the third week. However, D-galactose have no effect on the concentrations of serum ALP, AST, and ALT at the third week. These data suggested short-term exposure of Dgalactose might lead to hepatic damage, while long-term exposure of D-galactose might have no harmful effect on liver in piglets due to feedback regulation.

Previous investigations have reported that D-galactose treatment decreased the activities of SOD, CAT, and GSH-Px and elevated the level of MDA in mice serum, liver, and brain (Qiu et al., 2017; Zhou et al., 2017; Lin et al., 2018; Ma et al., 2018; Zhang X. et al., 2019; Wang et al., 2020). However, D-galactose increased the activity of CAT and decreased the activity of SOD, while fail to affect the activity of GSH-Px in erythrocytes of rats (Delwing-de Lima et al., 2017). These results showed that $\mathrm{D}$-galactose can induce oxidative stress and have various effects on different models. In this study, we also found that $5 \mathrm{~g} / \mathrm{kg}$ BW D-galactose decreased the activity of CAT at the first week, while increased the activity of CAT at the third week. $10 \mathrm{~g} / \mathrm{kg}$ BW D-galactose increased the activity of GSH-Px and the level of MDA at the second and third week. A study showed that antioxidant enzymes prevented hosts against oxidative stress by increasing their activities (Travacio and Llesuy, 1996). In addition, although it is still unclear that whether the oxidative stress is induced by weaning itself or other environmental factors, Zhu et al. (2012) found that weaning-induced oxidative stress decreased the activities of SOD and increased the level of MDA in serum of piglets (Zhu et al., 2012). Thus, we speculated that 
administration of D-galactose eventually could induce chronic oxidative stress in piglets via influencing the antioxidant enzymes activities.

Small intestine is the main organ for nutrient digestion and absorption in mammals and is highly susceptible to oxidative stress (Duan et al., 2014; Yin et al., 2015; Hussain et al., 2016). To further investigate whether D-galactose could induce chronic oxidative stress, the mRNA expressions of antioxidative related genes GPx1, CAT1, and MnSOD in jejunum and ileum were determined. In this current study, we found that 5 and $10 \mathrm{~g} / \mathrm{kg}$ BW D-galactose increased jejunal GPxland CAT1 expressions, respectively. 5, 10, and $20 \mathrm{~g} / \mathrm{kg} \mathrm{BW}$ D-galactose downregulated ileal GPx1 and CAT1 expression in piglets, which is consistent with the previous study (Mo et al., 2018). Evidence has showed that oxidative stress increased the mRNA expression of GPx1 in the jejunum of piglets (Cheng et al., 2019). Similarly, an in vitro study also showed that $\mathrm{D}$-galactose decreased the mRNA expressions of CuZnSOD, MnSOD, and GPx4 in IPECJ2 (Cao et al., 2020). These data showed that D-galactose could induce intestinal oxidative stress by modulating the expressions of antioxidant enzymes. Our previous study also found that essential nutrient which hav oxidative stress enhanced the mRNA expressions of CuZnSOD and GPx1 in the jejunum and ileum of piglets (He et al., 2018). Therefore, we speculated that in the jejunum, 5 and $10 \mathrm{~g} / \mathrm{kg} \mathrm{BW}$ D-galactose might exhibit a feedback regulatory mechanism against oxidative stress via enhancing GPx1 and CAT1 expression. However, in the ileum, D-galactose treatment inhibited antioxidant capacity since it decreased the expressions of GPx1 and CAT1. Additionally, we speculated that D-galactose might only induce alteration of antioxidant status in the ileum in piglets.

Additionally, amounting studies indicated that oxidative stress has direct correlation with gut microbiota in piglets and sows (Qiao et al., 2013; Li et al., 2019; Nie et al., 2019; Wang et al., 2019). A previous study has showed that Tenericutes is associated with improving apparent crude fiber digestibility in pigs (Niu et al., 2015). In addition to this, the relative abundance of Tenericutes is higher in healthy humans than individuals with metabolic disorders (Lim et al., 2017). Oxidative stress decreased the relative abundance of Tenericutes in rats (Zhou et al., 2018). Consistently, in this study, we also found that 10 and $20 \mathrm{~g} / \mathrm{kg} \mathrm{BW}$ D-galactose downregulated the relative abundance of Tenericutes. These results suggested that D-galactose supplementation had negative effect on metabolism in piglets. Lactobacillus frumenti appears to improve the antioxidant capacity in weaned piglets (Nie et al., 2019). Studies have showed that Lactobacillus and Bifidobacterium can alleviate oxidative stress via scavenging free radicals (Lin and Chang, 2000). However, in the current study, D-galactose supplementation had no effect on the relative abundance of Lactobacillus and Bifidobacterium. A study have showed that oxidative stress increased the relative abundance of Clostridium perfringens, E. coil, and enterococcus, while decreased the relative abundance of lactobacilli in mice (Qiao et al., 2013). Decreased relative abundance of Erysipelotrichia and Clostridia Chronic have been reported to contribute to gastrointestinal disease (Minamoto et al., 2015). In addition, injection of D-galactose increased the relative abundance of Firmicutes and Clostridiales, while decreased the relative abundance of Bacteroidetes and Lactobacillus in mice (Zhao et al., 2018). In the current study, D-galactose treatment decreased the relative abundance of Erysipelotrichia and Clostridia classes and Clostridiales and Erysipelotrichales orders. Based on these results, we infer that $\mathrm{D}$-galactose could reduce microbial diversity and further cause metabolic dysbiosis and intestinal diseases in piglets.

In conclusion, we suggested that the optimal modeling method is a final dosage of $10 \mathrm{~g} / \mathrm{kg} \mathrm{BW} /$ day D-galactose treated with weaned piglets for 3 weeks for D-galactose-induced chronic oxidative stress modeling. Additionally, administration of Dgalactose had negative effects on the growth performance and influenced gut microbiota in piglets.

\section{DATA AVAILABILITY STATEMENT}

The datasets presented in this study can be found in online repositories. The names of the repository/repositories and accession number(s) can be found in the article/supplementary material.

\section{ETHICS STATEMENT}

The animal study was reviewed and approved by Institute of Subtropical Agriculture, Chinese Academy of Sciences (2013020; Changsha, China). Written informed consent was obtained from the owners for the participation of their animals in this study.

\section{AUTHOR CONTRIBUTIONS}

$\mathrm{HH}, \mathrm{ZL}$, and JY conducted the study. JG, RH, and CW helped to perform the experiment. $\mathrm{LH}, \mathrm{XH}, \mathrm{GW}$, and TL helped to writing the manuscript. TL and YY designed the experiment and revised the manuscript. All authors contributed to the article and approved the submitted version.

\section{FUNDING}

This study was supported by the National Natural Science Foundation of China (Nos. 31872371 and 31902168), Hunan High-level Talent Gathering Project (2018RS3111), National Science Foundation for Outstanding Young Scholars of Hunan Province (2019JJ30017), Young Elite Scientists Sponsorship Program by CAST (2019-2021QNRC001), Changsha Science and Technology Key Program (kq1901090), and China Agriculture Research System (CARS-35).

\section{ACKNOWLEDGMENTS}

We are grateful to the Public Service Technology Center, Institute of Subtropical Agriculture, Chinese Academy of Sciences for technical support. 


\section{REFERENCES}

Ali, T., Badshah, H., Kim, T. H., and Kim, M. O. (2015). Melatonin attenuates D-galactose-induced memory impairment, neuroinflammation and neurodegeneration via RAGE/NF-KB/JNK signaling pathway in aging mouse model. J. Pineal Res. 58, 71-85. doi: 10.1111/jpi.12194

Andrade-Oliveira, V., Amano, M. T., Correa-Costa, M., Castoldi, A., Felizardo, R. J., de Almeida, D. C., et al. (2015). Gut bacteria products prevent AKI induced by ischemia-reperfusion. J. Am. Soc. Nephrol. 26, 1877-1888. doi: 10.1681/asn. 2014030288

Campbell, J. M., Crenshaw, J. D., and Polo, J. (2013). The biological stress of early weaned piglets. J. Anim. Sci. Biotechnol. 4:19. doi: 10.1186/2049-1891-4-19

Cao, G., Tao, F., Hu, Y., Li, Z., Zhang, Y., Deng, B., et al. (2019). Positive effects of a Clostridium butyricum-based compound probiotic on growth performance, immune responses, intestinal morphology, hypothalamic neurotransmitters, and colonic microbiota in weaned piglets. Food Funct. 10, 2926-2934. doi: 10.1039/c8fo02370k

Cao, S., Wang, C., Yan, J., Li, X., Wen, J., and Hu, C. (2020). Curcumin ameliorates oxidative stress-induced intestinal barrier injury and mitochondrial damage by promoting Parkin dependent mitophagy through AMPK-TFEB signal pathway. Free Radic. Biol. Med. 147, 8-22. doi: 10.1016/j.freeradbiomed.2019. 12.004

Cao, S., Wu, H., Wang, C., Zhang, Q., Jiao, L., Lin, F., et al. (2018). Diquat-induced oxidative stress increases intestinal permeability, impairs mitochondrial function, and triggers mitophagy in piglets1. J. Anim. Sci. 96, 1795-1805.

Cheng, Q., Jiang, S., Huang, L., Ge, J., Wang, Y., and Yang, W. (2019). Zearalenone induced oxidative stress in the jejunum in postweaning gilts through modulation of the Keap1-Nrf2 signaling pathway and relevant genes1. J. Anim. Sci. 97, 1722-1733. doi: 10.1093/jas/skz051

National Research Council (2012). Nutrient Requirements of Swine. Washington, DC: The National Academic Press.

da Silva, E. O., Gerez, J. R., Hohmann, M. S. N., Verri, W. A. Jr., and Bracarense, A. (2019). Phytic acid decreases oxidative stress and intestinal lesions induced by fumonisin $b_{1}$ and deoxynivalenol in intestinal explants of pigs. Toxins 11:18. doi: $10.3390 /$ toxins 11010018

Dam, B., Misra, A., and Banerjee, S. (2019). "Role of gut microbiota in combating oxidative stress," in Oxidative Stress in Microbial Diseases, eds S. Chakraborti, T. Chakraborti, D. Chattopadhyay, and C. Shaha (Singapore: Springer), 43-82.

Delwing-de Lima, D., Hennrich, S. B., Delwing-Dal Magro, D., Aurélio, J. G. M., Serpa, A. P., Augusto, T. W., et al. (2017). The effect of d-galactose induced oxidative stress on in vitro redox homeostasis in rat plasma and erythrocytes. Biomed. Pharmacother. 86, 686-693. doi: 10.1016/j.biopha.2016.12.011

Di Giancamillo, A., Rossi, R., Pastorelli, G., Deponti, D., Carollo, V., Casamassima, D., et al. (2015). The effects of dietary verbascoside on blood and liver oxidative stress status induced by a high n-6 polyunsaturated fatty acids diet in piglets. J. Anim. Sci. 93, 2849-2859. doi: 10.2527/jas.2014-8607

Duan, J., Yin, J., Ren, W., Liu, T., Cui, Z., Huang, X., et al. (2016). Dietary supplementation with L-glutamate and L-aspartate alleviates oxidative stress in weaned piglets challenged with hydrogen peroxide. Amino Acids 48, 53-64. doi: 10.1007/s00726-015-2065-3

Duan, J., Yin, J., Wu, M., Liao, P., Deng, D., Liu, G., et al. (2014). Dietary glutamate supplementation ameliorates mycotoxin-induced abnormalities in the intestinal structure and expression of amino acid transporters in young pigs. PLoS One 9:e112357. doi: 10.1371/journal.pone.0112357

Feng, C., Bai, K., Wang, A., Ge, X., Zhao, Y., Zhang, L., et al. (2018). Effects of dimethylglycine sodium salt supplementation on growth performance, hepatic antioxidant capacity, and mitochondria-related gene expression in weanling piglets born with low birth weight1. J. Anim. Sci. 96, 3791-3803. doi: 10.1093/ jas/sky233

He, L., Wu, J., Tang, W., Zhou, X., Lin, Q., Luo, F., et al. (2018). Prevention of oxidative stress by $\alpha$-ketoglutarate via activation of CAR signaling and modulation of the expression of key antioxidant-associated targets in vivo and in vitro. J. Agric. Food Chem. 66, 11273-11283. doi: 10.1021/acs.jafc.8b04470

He, L. Q., Zhou, X. H., Huang, N., Li, H., Cui, Z. J., Tian, J. Q., et al. (2017). Administration of alpha-ketoglutarate improves epithelial restitution under stress injury in early-weaning piglets. Oncotarget 8, 91965-91978. doi: 10. 18632/oncotarget. 20555
Hussain, T., Tan, B., Yin, Y., Blachier, F., Tossou, M. C. B., and Rahu, N. (2016). Oxidative stress and inflammation: what polyphenols can do for us? Oxidat. Med. Cell. Longev. 2016:7432797. doi: 10.1155/2016/7432797

Jiang, T., Sun, Q., and Chen, S. (2016). Oxidative stress: a major pathogenesis and potential therapeutic target of antioxidative agents in Parkinson's disease and Alzheimer's disease. Prog. Neurobiol. 147, 1-19. doi: 10.1016/j.pneurobio.2016. 07.005

Li, Y., Liu, H., Zhang, L., Yang, Y., Lin, Y., Zhuo, Y., et al. (2019). Maternal dietary fiber composition during gestation induces changes in offspring antioxidative capacity, inflammatory response, and gut microbiota in a sow model. Int. J. Mol. Sci. 21:31. doi: 10.3390/ijms21010031

Lim, M. Y., You, H. J., Yoon, H. S., Kwon, B., Lee, J. Y., Lee, S., et al. (2017). The effect of heritability and host genetics on the gut microbiota and metabolic syndrome. Gut 66, 1031-1038. doi: 10.1136/gutjnl-2015-311326

Lin, M. Y., and Chang, F. J. (2000). Antioxidative effect of intestinal bacteria Bifidobacterium longum ATCC 15708 and Lactobacillus acidophilus ATCC 4356. Dig. Dis. Sci. 45, 1617-1622. doi: 10.1023/a:1005577330695

Lin, X., Xia, Y., Wang, G., Xiong, Z., Zhang, H., Lai, F., et al. (2018). Lactobacillus plantarum AR501 alleviates the oxidative stress of D-galactose-induced aging mice liver by upregulation of Nrf2-mediated antioxidant enzyme expression. J. Food Sci. 83, 1990-1998. doi: 10.1111/1750-3841.14200

Luo, Z., Zhu, W., Guo, Q., Luo, W., Zhang, J., Xu, W., et al. (2016). Weaning induced hepatic oxidative stress, apoptosis, and aminotransferases through MAPK signaling pathways in piglets. Oxid. Med. Cell Longev. 2016:4768541. doi: $10.1155 / 2016 / 4768541$

Ma, Y., Ma, B., Shang, Y., Yin, Q., Wang, D., Xu, S., et al. (2018). Flavonoid-rich ethanol extract from the leaves of diospyros kaki attenuates D-galactose-induced oxidative stress and neuroinflammation-mediated brain aging in mice. Oxid. Med. Cell Longev. 2018:8938207. doi: 10.1155/2018/89 38207

Marciano, F., and Vajro, P. (2017). "Oxidative stress and gut microbiota * * conflict of interest: none," in Gastrointestinal Tissue, ed. J. Gracia-Sancho (Cambridge, MA: Academic Press), 113-123.

Minamoto, Y., Otoni, C. C., Steelman, S. M., Büyükleblebici, O., Steiner, J. M., Jergens, A. E., et al. (2015). Alteration of the fecal microbiota and serum metabolite profiles in dogs with idiopathic inflammatory bowel disease. Gut Microb. 6, 33-47. doi: 10.1080/19490976.2014.997612

Mo, Z.-Z., Lin, Z.-X., Su, Z.-R., Zheng, L., Li, H.-L., Xie, J.-H., et al. (2018). Angelica sinensis supercritical fluid $\mathrm{CO} 2$ extract attenuates D-galactoseinduced liver and kidney impairment in mice by suppressing oxidative stress and inflammation. J. Med. Food 21, 887-898. doi: 10.1089/jmf.2017.4061

Nie, Y., Hu, J., Hou, Q., Zheng, W., Zhang, X., Yang, T., et al. (2019). Lactobacillus frumenti improves antioxidant capacity via nitric oxide synthase 1 in intestinal epithelial cells. FASEB J. 33, 10705-10716. doi: 10.1096/fj.201900253RR

Niu, Q., Li, P., Hao, S., Zhang, Y., Kim, S. W., Li, H., et al. (2015). Dynamic distribution of the gut microbiota and the relationship with apparent crude fiber digestibility and growth stages in pigs. Sci. Rep. 5:9938. doi: 10.1038/srep09938

Pu, J., Tian, G., Li, B., Chen, D., He, J., Zheng, P., et al. (2016). Trace mineral overload induced hepatic oxidative damage and apoptosis in pigs with longterm high-level dietary mineral exposure. J. Agric. Food Chem. 64, 1841-1849. doi: 10.1021/acs.jafc.5b05613

Qian, Y., Zhang, J., Zhou, X., Yi, R., Mu, J., Long, X., et al. (2018). Lactobacillus plantarum CQPC11 isolated from sichuan pickled cabbages antagonizes d-galactose-induced oxidation and aging in mice. Molecules 23:3026. doi: 10 3390/molecules23113026

Qiao, Y., Sun, J., Ding, Y., Le, G., and Shi, Y. (2013). Alterations of the gut microbiota in high-fat diet mice is strongly linked to oxidative stress. Appl. Microbiol. Biotechnol. 97, 1689-1697. doi: 10.1007/s00253-012-4323-6

Qiu, Y., Ai, P.-F., Song, J.-J., Liu, C., and Li, Z.-W. (2017). Total flavonoid extract from Abelmoschus manihot (L.) medic flowers attenuates d-galactose-induced oxidative stress in mouse liver through the Nrf2 pathway. J. Med. Food 20, 557-567. doi: 10.1089/jmf.2016.3870

Qiu, Y., Yang, X., Wang, L., Gao, K., and Jiang, Z. (2019). L-Arginine inhibited inflammatory response and oxidative stress induced by Lipopolysaccharide via arginase-1 signaling in IPEC-J2 cells. Int. J. Mol. Sci. 20:1800. doi: 10.3390/ ijms 20071800

Rose, S., Bennuri, S. C., Davis, J. E., Wynne, R., Slattery, J. C., Tippett, M., et al. (2018). Butyrate enhances mitochondrial function during oxidative stress in cell 
lines from boys with autism. Transl. Psychiatry 8:42. doi: 10.1038/s41398-0170089-z

Rossi, R., Corino, C., Modina, S., and Di Giancamillo, A. (2019). Dietary verbascoside influences gut morphology and the expression of $\alpha$-transducin and $\alpha$-gustducin in the small intestine of weaned piglets exposed to n-6 polyunsaturated fatty acids-induced oxidative stress. Anim. Open Access J. MDPI 9:20. doi: 10.3390/ani9010020

Sha, J. Y., Zhou, Y. D., Yang, J. Y., Leng, J., Li, J. H., Hu, J. N., et al. (2019). Maltol (3Hydroxy-2-methyl-4-pyrone) slows d-galactose-induced brain aging process by damping the Nrf2/HO-1-mediated oxidative stress in mice. J. Agric. Food Chem. 67, 10342-10351. doi: 10.1021/acs.jafc.9b04614

Shan, Q., Lu, J., Zheng, Y., Li, J., Zhou, Z., Hu, B., et al. (2009). Purple sweet potato color ameliorates cognition deficits and attenuates oxidative damage and inflammation in aging mouse brain induced by d-galactose. J. Biomed. Biotechnol. 2009:564737. doi: 10.1155/2009/564737

Shen, Y., Wan, H., Zhu, J., Fang, Z., Che, L., Xu, S., et al. (2015). Fish oil and olive oil supplementation in late pregnancy and lactation differentially affect oxidative stress and inflammation in sows and piglets. Lipids 50, 647-658. doi: 10.1007/s11745-015-4024-X

Shen, Y.-X., Xu, S.-Y., Wei, W., Sun, X.-X., Yang, J., Liu, L.-H., et al. (2002). Melatonin reduces memory changes and neural oxidative damage in mice treated with D-galactose. J. Pineal Res. 32, 173-178. doi: 10.1034/j.1600-079x. 2002.10850.x

Shwe, T., Pratchayasakul, W., Chattipakorn, N., and Chattipakorn, S. C. (2018). Role of D-galactose-induced brain aging and its potential used for therapeutic interventions. Exp. Gerontol. 101, 13-36. doi: 10.1016/j.exger.2017.10.029

Sun, K., Yang, P., Zhao, R., Bai, Y., and Guo, Z. (2018). Matrine attenuates D-galactose-induced aging-related behavior in mice via inhibition of cellular senescence and oxidative stress. Oxid. Med. Cell Longev. 2018:7108604. doi: $10.1155 / 2018 / 7108604$

Thakur, M., Shaeib, F., Khan, S. N., Kohan-Ghadr, H. R., Jeelani, R., Aldhaheri, S. R., et al. (2017). Galactose and its metabolites deteriorate metaphase II mouse oocyte quality and subsequent embryo development by disrupting the spindle structure. Sci. Rep. 7:231. doi: 10.1038/s41598-017-00159-y

Travacio, M., and Llesuy, S. (1996). Antioxidant enzymes and their modification under oxidative stress conditions. Ciência Cult. 48, 9-13.

Vasquez, E. C., Pereira, T. M. C., Campos-Toimil, M., Baldo, M. P., and Peotta, V. A. (2019). Gut microbiota, diet, and chronic diseases: the role played by oxidative stress. Oxid. Med. Cell Longev. 2019:7092032. doi: 10.1155/2019/ 7092032

Wang, F., Zhou, H., Deng, L., Wang, L., Chen, J., and Zhou, X. (2020). Serine deficiency exacerbates inflammation and oxidative stress via microbiota-gutbrain axis in D-galactose-induced aging mice. Mediat. Inflamm. 2020:5821428. doi: $10.1155 / 2020 / 5821428$

Wang, H., Hu, C., Cheng, C., Cui, J., Ji, Y., Hao, X., et al. (2019). Unraveling the association of fecal microbiota and oxidative stress with stillbirth rate of sows. Theriogenology 136, 131-137. doi: 10.1016/j.theriogenology.2019.06.028

Wang, J., Zhang, H. J., Xu, L., Long, C., Samuel, K. G., Yue, H. Y., et al. (2016). Dietary supplementation of pyrroloquinoline quinone disodium protects against oxidative stress and liver damage in laying hens fed an oxidized sunflower oil-added diet. Animal 10, 1129-1136. doi: 10.1017/ s175173111600001x

Xu, Y. Q., Xing, Y. Y., Wang, Z. Q., Yan, S. M., and Shi, B. L. (2018). Preprotective effects of dietary chitosan supplementation against oxidative stress induced by diquat in weaned piglets. Cell Stress Chaperones 23, 703-710. doi: 10.1007/s12192-018-0882-5

Yahata, T., and Hamaoka, K. (2016). Oxidative stress and Kawasaki disease: how is oxidative stress involved from the acute stage to the chronic stage? Rheumatology 56, 6-13.

Yin, J., Li, Y., Han, H., Chen, S., Gao, J., Liu, G., et al. (2018). Melatonin reprogramming of gut microbiota improves lipid dysmetabolism in high-fat diet-fed mice. J. Pineal Res. 65:e12524. doi: 10.1111/jpi.1 2524

Yin, J., Li, Y., Zhu, X., Han, H., Ren, W., Chen, S., et al. (2017). Effects of longterm protein restriction on meat quality, muscle amino acids, and amino acid transporters in pigs. J. Agric. Food Chem. 65, 9297-9304. doi: 10.1021/acs.jafc. $7 \mathrm{~b} 02746$
Yin, J., Liu, M., Ren, W., Duan, J., Yang, G., Zhao, Y., et al. (2015). Effects of Dietary Supplementation with Glutamate and Aspartate on Diquat-Induced Oxidative Stress in Piglets. PLoS One 10:e0122893. doi: 10.1371/journal.pone.01 22893

Yin, J., Wu, M. M., Xiao, H., Ren, W. K., Duan, J. L., Yang, G., et al. (2014). Development of an antioxidant system after early weaning in piglets. J. Anim. Sci. 92, 612-619. doi: 10.2527/jas.2013-6986

Yu, K., Matzapetakis, M., Horvatić, A., Terré, M., Bach, A., Kuleš, J., et al. (2020). Metabolome and proteome changes in skeletal muscle and blood of pre-weaning calves fed leucine and threonine supplemented diets. J. Proteomics 216:103677. doi: 10.1016/j.jprot.2020.103677

Zhang, B., Li, L., Liu, Y., and Wang, Q. (2016). Antiviral mechanism study of gossypol and its Schiff base derivatives based on reactive oxygen species (ROS). RSC Adv. 6, 87637-87648. doi: 10.1039/C6RA1 4015G

Zhang, X., Wu, J.-Z., Lin, Z.-X., Yuan, Q.-J., Li, Y.-C., Liang, J.-L., et al. (2019). Ameliorative effect of supercritical fluid extract of Chrysanthemum indicum Linnén against D-galactose induced brain and liver injury in senescent mice via suppression of oxidative stress, inflammation and apoptosis. J. Ethnopharmacol. 234, 44-56. doi: 10.1016/j.jep.2018.12.050

Zhang, Z., Yang, H., Yang, J., Xie, J., Xu, J., Liu, C., et al. (2019). PseudoginsenosideF11 attenuates cognitive impairment by ameliorating oxidative stress and neuroinflammation in d-galactose-treated mice. Int. Immunopharmacol. 67, 78-86. doi: 10.1016/j.intimp.2018.11.026

Zhang, Y., Wang, Y., Chen, D., Yu, B., Zheng, P., Mao, X., et al. (2018). Dietary chlorogenic acid supplementation affects gut morphology, antioxidant capacity and intestinal selected bacterial populations in weaned piglets. Food Funct. 9, 4968-4978. doi: 10.1039/C8FO01126E

Zhao, J., Tian, F., Yan, S., Zhai, Q., Zhang, H., and Chen, W. (2018). Lactobacillus plantarum CCFM10 alleviating oxidative stress and restoring the gut microbiota in d-galactose-induced aging mice. Food Funct. 9, 917-924. doi: $10.1039 / \mathrm{c} 7$ fo01574g

Zheng, P., Yu, B., He, J., Yu, J., Mao, X., Luo, Y., et al. (2017). Arginine metabolism and its protective effects on intestinal health and functions in weaned piglets under oxidative stress induced by diquat. Br. J. Nutr. 117, 1495-1502. doi: 10.1017/S0007114517001519

Zhenyukh, O., Civantos, E., Ruiz-Ortega, M., Sánchez, M. S., Vázquez, C., Peiró, C., et al. (2017). High concentration of branched-chain amino acids promotes oxidative stress, inflammation and migration of human peripheral blood mononuclear cells via mTORC1 activation. Free Radic. Biol. Med. 104, 165-177. doi: 10.1016/j.freeradbiomed.2017.01.009

Zhou, J., Xiong, X., Wang, K.-X., Zou, L.-J., Ji, P., and Yin, Y.-L. (2018). Ethanolamine enhances intestinal functions by altering gut microbiome and mucosal anti-stress capacity in weaned rats. Br. J. Nutr. 120, 241-249. doi: $10.1017 / \mathrm{s} 0007114518001101$

Zhou, Y., Xu, Q., Dong, Y., Zhu, S., Song, S., and Sun, N. (2017). Supplementation of mussel peptides reduces aging phenotype, lipid deposition and oxidative stress in D-galactose-induce aging mice. J. Nutr. Health Aging 21, 1314-1320. doi: 10.1007/s12603-016-0862-3

Zhu, L. H., Zhao, K. L., Chen, X. L., and Xu, J. X. (2012). Impact of weaning and an antioxidant blend on intestinal barrier function and antioxidant status in pigs. J. Anim. Sci. 90, 2581-2589. doi: 10.2527/jas.2012-4444

Conflict of Interest: XH and GW are employed by the company Changsha Lvye Bio-Technology Co., Ltd.

The remaining authors declare that the research was conducted in the absence of any commercial or financial relationships that could be construed as a potential conflict of interest.

Copyright (c) 2021 Han, Liu, Yin, Gao, He, Wang, Hou, He, Wang, Li and Yin. This is an open-access article distributed under the terms of the Creative Commons Attribution License (CC BY). The use, distribution or reproduction in other forums is permitted, provided the original author(s) and the copyright owner(s) are credited and that the original publication in this journal is cited, in accordance with accepted academic practice. No use, distribution or reproduction is permitted which does not comply with these terms. 